\title{
A fundraising mechanism inspired by historical tontines: Theory and experimental evidence ${ }^{\succsim /}$
}

\author{
Andreas Lange ${ }^{\mathrm{a}, \mathrm{b}, *}$, John A. List ${ }^{\mathrm{c}, \mathrm{d}}$, Michael K. Price ${ }^{\mathrm{e}}$ \\ a AREC, The University of Maryland, 2200 Symons Hall, College Park, MD 20742-5535, United States \\ ${ }^{\mathrm{b}}$ ZEW, Germany \\ ${ }^{c}$ Department of Economics, University of Chicago, United States \\ ${ }^{\mathrm{d}}$ NBER, United States \\ e ARE, University of Nevada Reno, United States
}

Received 17 August 2006; received in revised form 23 February 2007; accepted 21 May 2007

Available online 6 June 2007

\begin{abstract}
The tontine, which is an interesting mixture of group annuity, group life insurance, and lottery, has a peculiar place in economic history. In the seventeenth and eighteenth centuries it played a major role in raising funds to finance public goods in Europe, but today it is rarely encountered outside of a dusty footnote in actuarial course notes or as a means to thicken the plot of a murder mystery. This study provides a formal model of individual contribution decisions under a modern variant of the historical tontine mechanism that is easily implemented by private charities. Our model incorporates desirable properties of the historical tontine to develop a mechanism to fund the private provision of a public good. The tontine-like mechanism we derive is predicted to outperform not only the voluntary contribution mechanism but also another widely used mechanism: charitable lotteries. Our experimental test of the instrument provides some evidence of the beneficial effects associated with implementing tontine-like schemes. We find that the mechanism has particular power in cases where agents are riskaverse or in situations where substantial asymmetries characterize individual preferences for the public good.

(C) 2007 Elsevier B.V. All rights reserved.
\end{abstract}

JEL classification: H41 (Public Goods); C91 (Design of Experiments)

Keywords: Tontines; Public goods; Fundraising; Lotteries; Experiments

\footnotetext{
is Seminar participants at the BBV celebration, the Guest Editors, and an anonymous reviewer provided particularly acute comments that shaped the manuscript. Shannon Price provided excellent research assistance. Andreas Lange gratefully acknowledges funding by the Deutsche Forschungsgemeinschaft (DFG) under grant LA 1333/2-1. Michael Price gratefully acknowledges funding by the Russell Sage foundation.

* Corresponding author. AREC, The University of Maryland, 2200 Symons Hall, College Park, MD 2074-5535, Unites States.

E-mail address: alange@arec.umd.edu (A. Lange).
} 
tontine: An annuity scheme wherein participants share certain benefits and on the death of any participant his benefits are redistributed among the remaining participants; can run for a fixed period of time or until the death of all but one participant. Webster's Online Dictionary

\section{Introduction}

The oldest standing bridge in London (Richmond Bridge), numerous public buildings and other municipality projects throughout the western world, and several wars, including the Nine Years' War, all share a common thread: they were wholly, or partially, funded by tontines. The idea of the tontine is believed to have originated in 1652, when an expatriate banker, Lorenzo Tonti, proposed a new mechanism for raising public funds to Cardinal Mazarin of France. ${ }^{1}$ Tonti advertised his idea as "A gold mine for the king..... treasure hidden away from the realm." The salesmanship of Tonti coupled with the difficulties associated with raising taxes in seventeenth century France led to an enthusiastic endorsement from King Louis XIV. While tontines, which are a mixture of group annuity, group life insurance, and lottery, prospered as a popular means for financing public goods for several decades, they have since been banned in Britain and the United States due to the incentives to murder other participants. ${ }^{2}$

Accordingly, this study does not try to revive tontines as a mechanism to finance government debt or provide a lifetime annuity for subscribers. Rather it sets out to explore a mechanism that incorporates desirable properties of the tontine, and evaluates the mechanism as a potential instrument used by a charitable organization in the context of a short-run capital campaign. We, therefore, intentionally abstract from the temporal aspects of historical tontines to concentrate on those features of tontines that a fundraiser can readily implement to improve upon the voluntary provision of public goods in an atemporal context.

In this light, a natural comparison to make is that of tontines and other "demand side" instruments that are regularly employed by charities and fundraisers: rebates and matching (Eckel and Grossman, 2003), seed money (Andreoni, 1998; List and Lucking-Reiley, 2002), charitable auctions (Engers and McManus, 2002; Goeree et al., 2005) or raffles and lotteries (Morgan, 2000; Morgan and Sefton, 2000; Landry et al., 2006; Lange et al., 2007). ${ }^{3}$ We add to this literature by investigating the performance and the optimal design of a mechanism that shares important qualities with the historical tontine but is easily implemented by private charities.

We begin our study with a brief history of tontines, focusing on the elements of the historical instrument that yield a model of the new fundraising mechanism. The key innovation concerns two relevant properties: while the probability for an agent to compete with a given subset of participants for part of the prize is exogenously given (historically the survival probability), the payoffs to an agent depend on his or her relative contribution compared to that of other competing

\footnotetext{
${ }^{1}$ Similar mechanisms are believed to have been employed in the Roman Empire several centuries earlier. Tonti's mechanism should not be confused with the tontines in Western Africa, which are small, informal savings and loan associations similar to ROSCAs (Rotating Savings and Credit Associations).

2 This allure of the tontine has led to a fantastic plot device for detective story writers (the interested reader should see, e.g., The Wrong Box by Robert Louis Stevenson, which was made into a film in 1966 starring Peter Cook, Dudley Moore, Ralph Richardson, Michael Caine, and Tony Hancock).

${ }^{3}$ In turn, this literature draws from the numerous papers that have studied mechanisms to alleviate the tendency of agents to free-ride (see e.g., Bergstrom et al., 1986; Groves and Ledyard, 1977; Walker, 1981; Bagnoli and McKee, 1991; Varian, 1994; Falkinger, 1996).
} 
participants. ${ }^{4}$ For agents with identical valuations of the public good, we then outline the conditions that define an optimal tontine-one that maximizes total group contribution levels. Properties of tontines are also explored upon relaxation of symmetry. We then compare the performance of the tontine to a popular fundraising scheme used today: lotteries (see, e.g., Morgan, 2000; Lange et al., 2007).

Our main findings are as follows: For agents with identical valuations of the public good, (i) the optimal tontine consists of all agents receiving a fixed "prize" amount equal to a percentage of their total contribution, i.e. similar to an endogenous rebate scheme, (ii) contribution levels in this optimal tontine are identical to those of risk-neutral agents in an equivalently valued singleprize lottery, and (iii) contribution levels for the optimal tontine are independent of risk-aversion. Our tontine-inspired mechanism thus induces greater contributions (and therefore public good provision levels) than lotteries when agents are risk-averse.

In cases of asymmetric individual valuations for the public good, tontines should distribute only part of the prize among all agents, with the remainder being distributed across a subset of randomly drawn agents (corresponding to "surviving" players in the historical tontine). Such a scheme resembles features of the historical tontine and is demonstrated to yield higher contributions than the optimal lottery. Further, this mechanism can obtain close to full participation compared to partial participation in the lottery mechanism. This finding is important in light of the fact that fundraising strategists typically rank building a "donor development pyramid" as the most important aspect of a successful long-term fundraising effort.

We test these predictions using a set of experimental treatments carried out in the laboratory. These treatments compare the outcomes of the voluntary contribution mechanism (VCM), the single and multiple prize lotteries, the rebate scheme, and a tontine which pays half the prize as a rebate and distributes the remainder among two randomly drawn players. The experimental results suggest that tontines lead to higher contribution levels than the VCM. Compared to lotteries, tontines are found to have beneficial effects in two cases: i) when substantial asymmetries of preferences for the public good exist, and ii) when agents are sufficiently risk-averse.

We close the study with a brief summary of the paper's contributions. We argue that our results have implications for empiricists and practitioners in the design of fundraising campaigns. Further, they provide useful avenues for future theoretical work on voluntary provisioning of public goods.

\section{Tontines throughout history}

Lorenzo Tonti was a Neopolitan of little distinction until his sponsor, Cardinal Mazarin of France, who was responsible for the financial health of France, supported his position in the court of the French King in the 1650s. In this position, Tonti proposed a form of a life contingent annuity with survivorship benefits, whereby subscribers, who were grouped into different age classes, would make a one-time payment of 300 livres to the government. Each year, the government would make a payment to each group equaling $5 \%$ of the total capital contributed by that group. These payments would be distributed among the surviving group members based upon each agent's share of total group contributions. The government's debt obligation would cease with the death of the last member of each group. Although the plan was supported

\footnotetext{
${ }^{4}$ The astute reader will notice that these features reverse the fundamental characteristics of a widely-used fundraising instrument: charitable lotteries. As we discuss below, how such a reversal of the role of probabilities and payoffs affects the performance of such an instrument for public good provision is unknown.
} 
enthusiastically by Louis XIV, Tonti's plan was ultimately rejected by the French Parliament (Weir, 1989).

While the Netherlands started a successful tontine in 1670, it was not until 1689 that France offered its first national tontine to help finance the Nine Years' War. The design was quite similar to that originally proposed by Tonti. Later offerings in France coincided with peaks in national capital demand during periods of war and were generally successful in raising the sought-after capital. During France's four major wars of this period, national tontine offerings raised approximately 110 million livres from around 110,000 individuals.

Contrary to the relative success enjoyed by France, tontine offerings in England often failed to raise the desired capital. England provided its first national tontine in 1693; this initial tontine generated but a tenth of the one million pounds set as its goal. Yet England did successfully use the tontine to fund many public projects, including construction of the Richmond Bridge, claimed to be the oldest standing "London" Bridge.

While the use of tontines to finance government projects was predominately a European endeavour, the notion that tontines could be used as a means to finance national debt has a historical basis in the U.S. as well. Faced with growing principal liability on national debt, Alexander Hamilton proposed a national tontine in the U.S. in his 1790 Report Relative to a Provision for the Support of Public Credit (Jennings et al., 1988). Hamilton's proposal was to reduce principal repayments on national debt by converting old debt with principal that was repayable at the discretion of the government into debt demanding no return on principal.

The structure of the tontine that Hamilton proposed was inspired by a tontine originally proposed by William Pitt in 1789 . The proposed tontine included six age classes, and shares in the tontine would be sold for $\$ 200$ with no limit on the number of shares that any agent could purchase. Individuals could subscribe on their own lives or on the lives of others nominated by them. Hamilton proposed a freeze component on debt repayment, however: the annuities of subscribers who passed away would be divided among living subscribers until only $20 \%$ of the original subscribers remained. Once this threshold was reached, the payments to remaining survivors would be frozen for the duration of their lives (Dunbar, 1888).

\subsection{Tontine insurance in the United States}

While tontines proper were not used after the eighteenth century, an adaptation of the tontine was implemented in the U.S. life insurance market in 1868. Tontine insurance was introduced in 1868 by the Equitable Life Assurance Society of the U.S. Under tontine insurance, premiums served two distinct purposes: (i) provision of standard life insurance benefits and (ii) creation of an individual investment fund. Policyholders deferred receipt of the dividend payments which were pooled and invested by the insurance company on behalf of the policyholders for a specified time period. At the end of this period, the fund plus the investment earnings (which could be received as either cash or a fully paid life annuity) were divided proportionately among the entire active, surviving policyholders. Beneficiaries of policyholders who passed away before the end of the tontine period received the specified death benefits, but had no claim on the tontine fund money (Ransom and Sutch, 1987).

Conceptually, tontine insurance had several advantages relative to a standard life insurance policy. Policyholders were able to secure life insurance plus create a retirement fund. Survivors could receive a generous rate of return on these investments if a large proportion of other group members were to pass away or allow their policy to lapse. Tontine insurance provided an opportunity for young individuals to save for retirement by providing a low-risk, high-yield 
investment fund available on an installment plan. Unfortunately, corruption by the insurance companies led to the prohibition of tontine insurance sales by 1906 (Ransom and Sutch, 1987).

\section{Using tontines for voluntary provision of public goods}

Historical tontines were designed to combine features of group-annuity and life insurance with the provision of public goods. As these features require long-term commitment and credibility of the organizing entity, it may be difficult for private fundraisers to implement a mechanism resembling the historical tontine. We therefore focus on those characteristics of tontines that a fundraiser can readily use to improve upon the voluntary provision of public goods in an atemporal context, e.g., a charity event. ${ }^{5}$ In this regard, we view the most essential characteristic of tontines as follows: while the probability for an agent to compete with a given subset of participants for part of the prize is exogenously given, the payoffs to an agent depend on his or her relative contribution compared to that of other competing participants.

This feature reverses the fundamental characteristics of a widely-used fundraising instrument, charitable lotteries, whereby the payoffs (prizes) are exogenously given while the probabilities of winning depend on the (relative) contribution level of an agent. How this reversal of the role of probabilities and payoffs affects the performance of such an instrument for public good provision is unknown to our best knowledge. To model a mechanism for public good provision that shares similarities with the historical tontine (and which we therefore refer to as "tontine" in the remainder of the paper), we must first define the utility structure of agents and their probabilities of sharing a particular prize with a set of players.

\subsection{The probability structure}

We consider a set $\Omega=\{1, \ldots, n\}$ of $n$ agents. A total prize $P$ can be split into $T$ parts $P_{t}$ $\left(P=\sum_{t=1}^{T} P_{t}\right)$ - corresponding to the $t=1, \ldots, T$ periods in the historical tontine. We define a probability structure by

$$
\pi: 2^{\Omega \times T} \rightarrow[0,1]
$$

such that $\pi\left(S_{1}, \ldots, S_{T}\right)$ denotes the probability that subsets $S_{t} \subseteq \Omega(t=1, \ldots, T)$ compete for the prizes $P_{t}$. Since we are interested in tontines as a fundraising mechanism that does not discriminate amongst players, we assume that the probability of competing for a given prize $P_{t}$ is independent of an agent's identity. That is, for any permutation $\chi: \Omega \rightarrow \Omega$ of players we assume that $\pi\left(S_{1}, \ldots, S_{T}\right)=$ $\pi\left(\tilde{\chi}\left(S_{1}\right), \ldots, \tilde{\chi}\left(S_{\mathrm{T}}\right)\right)$ where $\tilde{\chi}(S)=\left\{i \in \Omega \mid \chi^{-1}(i) \in S\right\}$.

Differently from the historical tontine where the probabilities were given by the likelihood that a set of players was alive in a given period, in our tontine-inspired fundraising device, a charity can design the probability structure in an atemporal context to optimize total contributions to the public good.

\footnotetext{
${ }^{5}$ In a similar spirit, as private charities lack the ability to legally and credibly implement the types of taxation and reallocation schemes available to government organizations, we do not evaluate the performance of our mechanism relative to the class of mechanisms available to government entities. Rather, we concentrate on evaluating the performance of our mechanism relative to only that class of mechanisms that are feasible for private charities, such as charitable lotteries.
} 


\subsection{The basic model}

Consider an agent $i$ with (ex post) utility given by:

$$
U_{i}=u_{i}\left(y_{i}+h_{i}(G)\right)
$$

where $y_{i}$ is a numeraire and $G$ the provision level of the public good. We assume $h_{i}(G)$ is increasing and concave in the level of the public $\operatorname{good}\left(h_{i}^{\prime}(\bullet)>0, h_{i}^{\prime \prime}(\bullet) \leq 0\right)$. ${ }^{6}$ Further, we employ the standard assumption in the public goods literature that it is socially desirable to provide a positive amount of the public good, i.e., $\sum_{i} h_{i}^{\prime}(0)>1$. We later interpret $u_{i}(\bullet)$ as a Bernoulli function of a risk-averse decision maker, i.e. $u_{i}^{\prime}>0, u_{i}^{\prime \prime} \leq 0$.

Given an initial endowment $w_{i}$ of wealth (income), the choice facing the agent is to determine the amount $b_{i} \leq w_{i}$ of wealth to invest in the tontine. We assume that wealth constraints are nonbinding for all agents. ${ }^{7}$ Investment $b_{i}$ in the tontine provides the agent with an uncertain monetary return $x_{i}$ that is dependent upon own contributions and those of all other members of a group:

$$
U_{i}=u_{i}\left(w_{i}+x_{i}-b_{i}+h_{i}(G)\right) .
$$

We assume that the tontine pays different prizes $P_{t} \geq 0$ with an aggregate prize allocation of $\sum_{t=1}^{T} P_{t}=P$ and that the level of public good provision equals the total contribution minus the aggregate prize level:

$$
G=B-P=\sum_{i=1}^{n} b_{i}-\sum_{t=1}^{T} P_{t}
$$

provided contributions cover the prize payments and $G=0$ otherwise. ${ }^{8}$

For each prize $P_{t}$, a randomly selected group of players, $S_{t}$, "competes": they receive a payment that is determined by their relative contribution level, i.e. a player $i \in S_{t}$ receives a payment $\frac{b_{i}}{B-B\left(S_{t}\right)} P_{t}$ where $B-B\left(S_{t}\right)$ is the sum of the contributions made by the set $S_{t}$ of players. The total tontine payment to a player is given by

$$
P_{i}(S)=\sum_{t=1}^{T} P_{t} \frac{b_{i}}{B\left(S_{t}\right)} 1_{\left[i \in S_{t}\right]} .
$$

where $1_{\left[i \in S_{t}\right]}=1$ if and only if $i \in S_{t}$ and 0 otherwise. Given these definitions, we can fully characterize our tontine-inspired mechanism by

$$
\left(\Omega, T,\left(P_{1}, \ldots, P_{T}\right), \pi\right)
$$

\footnotetext{
${ }^{6}$ For studies that relax the assumption of utility being dependent upon only the level of the public good, see Sugden (1982, 1984) and Andreoni (1990). These theories suggest that if one were to rewrite utility such that is a function of both the level of the funds raised and one's own contribution, then the standard result of free-riding behavior can be reversed.

${ }^{7}$ Generally, there is the possibility of facing a binding budget constraint — especially for large prize levels in our theory. However, we wish to remain true to the spirit of the analysis of alternative mechanisms, such as charitable lotteries, which usually abstracts from binding wealth constraints (see Morgan, 2000, footnote 9). All of the comparisons in performance between the mechanisms studied in this paper and the alternative lottery schemes are therefore valid.

${ }^{8}$ Note that in the equilibria of the optimal tontine mechanism derived below, contributions always cover the prize payments.
} 
where $\Omega$ is the set of players, $T$ the number of prizes, $\pi$ a probability structure as defined in the previous section, and $\left(P_{1}, \ldots, P_{T}\right)$ the prize distribution.

We now consider the optimal tontine design. In particular, we address the question of how a charity with a fixed prize budget, $P$, should allocate this prize money across prizes and choose the probability structure to maximize total contributions.

Given a probability structure $\pi$, the ex ante expected utility of player $i$ is given by

$$
\mathrm{EU}_{i}=\sum_{S=\left(S_{1}, \ldots, S_{T}\right) \in 2^{\Omega \times T}} \pi(S) u_{i}\left(w_{i}-b_{i}+h_{i}(B-P)+P_{i}(S)\right)
$$

Differentiating expression (1) with respect to $b_{i}$ gives the first order conditions defining agent $i$ 's optimal contribution level:

$$
\begin{aligned}
& 0=\sum_{S=\left(S_{1}, \ldots, S_{T}\right) \in 2^{\Omega \times T}} \pi(S) u_{i}{ }^{\prime}(\bullet)\left[-1+h_{i}{ }^{\prime}(\bullet)+\sum_{t=1}^{T} P_{t} \frac{B\left(S_{t}\right)-b_{i}}{B\left(S_{t}\right)^{2}} 1_{\left[i \in S_{t}\right]}\right] \quad \text { for } i \in \Omega_{P} \\
& 0 \geq \sum_{S=\left(S_{1}, \ldots, S_{T}\right) \in 2^{\Omega \times T}} \pi(S) u_{i}{ }^{\prime}(\bullet)\left[-1+h_{i}{ }^{\prime}(\bullet)+\sum_{t=1}^{T} P_{t} \frac{1}{B\left(S_{t}\right)} 1_{\left[i \in S_{t}\right]}\right] \quad \text { for } i \notin \Omega_{P} .
\end{aligned}
$$

where $\Omega_{P}$ denotes the set of players with positive contributions.

\subsection{Tontines for agents with symmetric valuation of the public good}

We first consider the case of agents with identical valuation of the public good $\left(h_{i}(G)=h(G)\right)$. In this special case, under our model differences in equilibrium contributions can only occur due to differences in the risk attitudes of players. Yet, we show that the optimal tontine completely avoids a randomization of the set of competing players, effectively eliminating all risk from the decision problem. That is, the optimal tontine can be characterized by $T=1$ and $\pi(\Omega)=1$ : the total prize money is distributed among all players according to their relative contributions. The optimal tontine, therefore, corresponds to a rebate mechanism whereby the rebate rate is endogenously determined by contribution shares. We prove this result formally in the following proposition:

\section{Proposition 1. Optimal tontine-Symmetric risk-neutral agents}

If agents value the public good identically, contributions to the public good using a tontine are maximal if the total prize is distributed among all players according to their respective contribution shares.

Proof. See Appendix A.

For the optimal tontine, players are not subject to risky payoff streams. Since all players value the public good identically, the equilibrium is given by the symmetric version of first-order condition (2):

$$
1-h^{\prime}(\bullet)=\frac{B-b_{i}}{B^{2}} \sum_{t=1}^{T} P_{t}=\frac{B-b_{i}}{B^{2}} P
$$


Given our symmetry assumption, all $n$ agents contribute the same amount $(\bar{b})$ which generates a total contribution level $(\bar{B})$ for the optimal tontine given by

$$
n \bar{b}=\bar{B} \quad \bar{B}\left(1-h^{\prime}(\bar{B}-P)\right)=\frac{n-1}{n} P .
$$

The optimal tontine for symmetric agents, therefore, has a simple structure: all agents receive a rebate proportional to their contribution relative to that of the group. Given the contribution of all other agents, the tontine payment to agent $i$ under the tontine is given by $\frac{b_{i}}{B} P$, where $P$ denotes the prize level.

The total payoff to a player is therefore given by $w_{i}-b_{i}+h(B-P)+\frac{b_{i}}{B} P$, which can also be interpreted as the expected payoff in Morgan's (2000) risk-neutral one-prize lottery. All of his results therefore apply. In particular, contributions will exceed the prize level $P$ and raise a positive amount of money for the public good net of prize payments as

$$
P\left(1-h^{\prime}(0)\right)>\frac{n-1}{n} P \Leftrightarrow n h^{\prime}(0)>1,
$$

which coincides with the condition for a public good. ${ }^{9}$

We summarize these results as follows:

\section{Proposition 2. Contribution levels for optimal tontines-symmetric players}

For players with identical valuation of the public good, the optimal tontine raises contributions in excess of the prize-level $P$. The provision level of the public good is increasing in $P$.

In theory, our optimal tontine thus ensures net public good provision assuming an interior equilibria. As a practical matter, it should be noted that regardless of whether total contributions are sufficient to cover the prize allocation, we assume that all prize obligations will be paid by the charity. While this may seem a precarious situation for single-shot games in the real world, it is important to recognize the dynamic nature of charitable fundraising. For example, a charity might decide to run a loss from a charity event if by doing so it can generate a warm list of potential donors which reduces the solicitation costs in subsequent fundraising drives. In fact, this longterm aspect is invaluable as start-up fundraisers typically lose money in their first few attempts (see, e.g., Sargeant et al., 2006).

\subsection{Tontines and risk-aversion}

The tontine is equivalent to a single-prize lottery in expected payoff terms, but the tontinerebate mechanism induces a certain payoff. That is, in equilibrium players are not exposed to risk. Equilibrium contributions therefore do not depend on the risk posture of agents. This is different from lotteries that pay one prize to a randomly determined winner. Hence, the payoff stream for

\footnotetext{
${ }^{9}$ The optimal tontine that we study in this paper provides a rebate (subsidy) on individual contributions to the public good. This feature resembles the study relating government subsidies and contributions to a public good by Andreoni and Bergstrom (1996). In their case, however, subsidies are financed by taxes, whereas in our model the rebates are taken out of the contribution to the public good. The provision of the public good therefore does not depend on the possibility of enforcing tax payments. To balance the budget, subsidy rates in our model are not exogenously fixed but endogenously given by the individual relative to total contributions.
} 
the single-prize lottery is risky, and risk-averse agents will contribute less than their risk-neutral counterparts (see Lange et al., 2007). ${ }^{10}$ We summarize this notion in our next proposition:

\section{Proposition 3. Tontines for risk-averse players}

Individual contributions under the tontine that distributes among all participating players are independent of the risk posture of agents. If agents are risk-averse but symmetric with respect to their valuation of the public good, it dominates any lottery as a fundraising instrument.

Proposition 3 highlights two reasons why fundraisers may prefer to implement a tontine rather than a charitable lottery: (i) the independence of contributions and risk posture under a tontine and (ii) the superiority of tontines for risk-averse agents. Hence, it is not necessary for the fundraiser to have prior beliefs over the risk preference of a potential donor pool when designing the "optimal" fundraising mechanism as is the case for charitable lotteries.

\subsection{Tontines with heterogeneous agents}

The optimal tontine for players with identical valuations of the public good coincides with a pure rebate scheme. Tontines that deviate from the pure rebate scheme can lead to both higher contributions and higher participation rates if agents have heterogeneous valuations for the public good, however. Because contributions under such a mechanism (when optimally implemented) exceed those elicited via the rebate scheme, the contribution level for symmetric, risk-neutral agents in a single-prize lottery provides a lower bound on equilibrium donations. As Morgan (2000) has shown that contributions under a single-prize lottery are sufficient to cover the prize payments in such an environment, we need only invoke his result to show that contributions under the class of mechanisms we consider are sufficient to cover prize payments.

The following proposition shows that one can increase participation rates by deviating from the pure rebate scheme when agents have heterogeneous valuations for the public good:

\section{Proposition 4. Participation in tontines}

If for $P_{t}>0$ and $k_{t}$ there exists $\left(S_{1}, \ldots, S_{T}\right)$ with $k_{t}=\# S_{t}$ for all $t$ such that $\pi\left(S_{t}, S_{-t}\right)>0$, then at least $n-k_{t}+1$ players contribute to the tontine.

Proof. See Appendix A.

In particular, one can guarantee the participation of at least all but one agent by having a positive probability of only two agents competing for a prize $P_{t}>0$. Additionally, Proposition 4 implies that even a slight deviation from the rebate scheme can lead to a substantial increase in participation rates. This finding could be of potential interest for fundraisers who desire to create a "warm" list of donors that can be specifically targeted in subsequent fundraising drives. ${ }^{11}$

Besides increasing participation rates, a deviation from the rebate scheme can also induce larger contribution rates if players have heterogeneous valuations for the public good. To show

\footnotetext{
${ }^{10}$ Lange et al. (2007) concentrate on preferences which show constant absolute risk aversion. The dominance results generalizes to Bernoulli functions with convex marginal utility, i.e. which satisfy $u^{\prime \prime \prime} \geq 0$.

${ }^{11}$ As Landry et al. (2006) note, the warm list is invaluable in light of the fact that fundraising strategists typically rank building a "donor development pyramid" as the most important aspect of a successful long-term fundraising effort.
} 
this, we consider the case of risk-neutral agents for which only the expected prize payment is essential in determining contributions. As we assumed that the probability structure of the tontineinspired mechanism does not depend upon the identity of agents, any tontine for risk-neutral players can be equivalently modeled by specifying the prize level $P_{t}(t=1, \ldots, n-1)$ which is distributed among a set of $t$ randomly drawn agents. That is, the tontine is given by

$$
T=n-1, \quad \pi\left(S_{1}, \ldots, S_{T}\right)= \begin{cases}\Pi_{t=1}^{T}\left(\begin{array}{l}
n \\
k_{t}
\end{array}\right)^{-1} & \text { if } k_{t}=\# S_{t}=n+1-t \text { for all } t \\
0 & \text { otherwise }\end{cases}
$$

For such a tontine, the first order condition (2) can be rewritten as

$$
\begin{aligned}
& 1-h_{i}{ }^{\prime}(\bullet)=\sum_{t=1}^{n-1} P_{t}\left(\begin{array}{c}
n \\
n+1-t
\end{array}\right)^{-1} \sum_{S \subseteq \Omega, \# S=n+1-t} \frac{B\left(S_{t}\right)-b_{i}}{B\left(S_{t}\right)^{2}} 1_{\left[i \in S_{t}\right]} \quad \text { for } i \in \Omega_{P} \\
& 1-h_{i}{ }^{\prime}(\bullet) \geq=\sum_{t=1}^{n-1} P_{t}\left(\begin{array}{c}
n \\
n+1-t
\end{array}\right)^{-1} \sum_{S \subseteq \Omega, \# S=n+1-t} \frac{1}{B\left(S_{t}\right)^{2}} 1_{\left[i \in S_{t}\right]} \quad \text { for } i \notin \Omega_{P} .
\end{aligned}
$$

where $\Omega_{P}$ denotes the set of contributing players.

This describes a simple mechanism that can readily be applied in fundraising events: (i) the fundraiser distributes a portion of the total prize budget among the set of all participants according to their relative contribution shares, (ii) for any given portion of the total prize, the fundraiser randomly selects a predetermined number of players from the set of all participants, (iii) this portion of the prize is then allocated amongst this randomly drawn subset of participants according to their relative contribution shares.

For example, one could distribute part of the prize as a rebate among all participants and then randomly determine two agents who share the remaining prize money. The following proposition shows that for heterogeneous agents even such a simple-structured tontine can increase the total provision level of the public good.

\section{Proposition 5. Tontines-Heterogeneous agents}

If agents are heterogeneous with respect to their valuation of the public good, then contributions can be increased by using a tontine which combines a rebate scheme with an additional prize distributed among two randomly drawn agents (i.e. condition (5) with $P_{t}=0$ for $\left.t=2, \ldots . n-2, P_{n-1}=\varepsilon, P_{1}=P-\varepsilon\right)$ if

$$
\begin{aligned}
\sum_{S \subseteq \Omega_{0}, \# S=2} & \frac{k_{0}-H\left(\Omega_{0}\right)}{2-2 H\left(\Omega_{0}\right)+H(S)\left(k_{0}-1\right)} \\
& +\sum_{S \subseteq \Omega_{1}, \# S=2} \frac{1}{k_{1}-1} \frac{k_{0}-H\left(\Omega_{0}\right)}{-2-H(S)\left(k_{0}-1\right)+2 H\left(\Omega_{0}\right)}>\frac{n(n-1)}{2}\left(k_{0}-1\right)
\end{aligned}
$$

where $\Omega_{0}$ denotes the set of $k_{0}$ players with positive contributions in the pure rebate scheme $(\varepsilon=0)$ and $\Omega_{1}$ is the set of $k_{1}$ players who contribute zero under the pure rebate scheme but elect to contribute a positive amount under the two stage mechanism (i.e., for arbitrarily small $\varepsilon>0$ ). Marginal valuations at $\varepsilon=0$ are denoted by $H(S)=\sum_{i \in S} h_{i}{ }^{\prime}(\bullet)$. 
Proof. See Appendix A.

Before proceeding a few comments on Proposition 5 and the proposed two-stage mechanism are warranted. The sets $\Omega_{0}$ and $\Omega_{1}$ are not relevant for the random selection process. Importantly, the probability that an agent in $\Omega_{0}$ is selected to compete for the second-stage allocation is identical to the probability that an agent in the set $\Omega_{1}$ is selected. Hence, the charitable organization need not observe individual preferences to effectively implement the two-stage mechanism. Rather, all the charitable organization need observe is that there exists a set of agents who are approximately indifferent to contributing under the pure rebate scheme.

A direct implication of Proposition 5 is that a fundraiser can increase contributions by deviating from the pure rebate scheme if there are only two players on the margin of contributing, i.e. if $2-2 H\left(\Omega_{0}\right)+H(S)\left(k_{0}-1\right)=0$. As an illustration of Proposition 5, consider the following example:

Example 1. Assume two types of agents with linear marginal valuations of the public good: $h_{i}^{\prime}(B)=$ $\bar{h}_{i} B$ with $\bar{h}_{1}=0.75$. The number of agents of both types is given by $n_{1}=n_{2}=2$. Applying the first order condition yields the contribution under the pure rebate scheme:

$$
B_{0} / P=\left\{\begin{array}{cc}
\frac{1.5}{1.25-\bar{h}_{2}} & \text { if } \bar{h}_{2} \geq 0.5 \\
2 & \text { if } \bar{h}_{2}<0.5
\end{array}\right.
$$

Type 2 agents only contribute to the pure rebate scheme if $\bar{h}_{2}>0.5$. However, solving condition (7), it can be shown that one can improve upon the pure rebate scheme if $0.478<\bar{h}_{2}<0.576$.

In the prior subsection, we showed that a tontine with $P_{0}=P$ coincides with a single-prize lottery. Lange et al. (2007) show that it is possible to improve upon the single-prize lottery by providing (at least) a second prize if agents are heterogeneous and

$$
\left(k_{0}-2\right) \sum_{i \in \Omega_{0}} \frac{b_{i}}{B_{0}-b_{i}}>k_{0} \Leftrightarrow\left(1-H\left(\Omega_{0}\right) / k_{0}\right) \sum_{i \in \Omega_{0}} \frac{1}{1-h_{i}{ }^{\prime}}>\frac{\left(k_{0}-1\right)^{2}}{k_{0}-2}
$$

Comparing this criterion with the analogous conditions derived in Proposition 1, and upon expansion of Example 1, we illustrate conditions under which public good provision can be increased using a tontine rather than the optimal lottery:

Example 2. Consider the situation in Example 1. Using lotteries, condition (8) shows that one could never improve upon the single-prize lottery by introducing a second prize if $\bar{h}_{2}<0.5$. However, even for $\bar{h}_{2}>0.5$, condition (8) cannot be satisfied and an optimally designed tontine will outperform any lottery for marginal valuations of the Type 2 agents in the range $0.478<\bar{h}_{2}<0.576$.

The following proposition summarizes these findings:

\section{Proposition 6. Tontines versus lotteries-Heterogeneous agents}

If agents are risk-neutral and heterogeneous with respect to their valuation of the public good, then there are situations in which appropriately designed tontines outperform lotteries.

While we have provided an arbitrary example to illustrate this result, in real-world applications there are usually agents who are approximately indifferent between contributing to a public good. 
Table 1

Experimental design

\begin{tabular}{|c|c|c|}
\hline & Session 1 & Session 2 \\
\hline \multicolumn{3}{|l|}{ Symmetric-VCM } \\
\hline $\mathrm{MPCR}=0.30$ & $N=20$ subjects & \\
\hline Endowment $=100$ & 10 rounds & \\
\hline \multicolumn{3}{|l|}{ Symmetric-SPL } \\
\hline $\mathrm{MPCR}=0.30$ & $N=20$ subjects & $N=16$ subjects \\
\hline Endowment $=100$ & 10 rounds & 10 rounds \\
\hline \multicolumn{3}{|l|}{ Prize $=80$} \\
\hline \multicolumn{3}{|l|}{ Symmetric-REB } \\
\hline $\mathrm{MPCR}=0.30$ & $N=16$ subjects & $N=24$ subjects \\
\hline Endowment $=100$ & 10 rounds & 10 rounds \\
\hline \multicolumn{3}{|l|}{ Prize $=80$} \\
\hline \multicolumn{3}{|l|}{ Symmetric-TON } \\
\hline $\mathrm{MPCR}=0.30$ & $N=16$ subjects & $N=20$ subjects \\
\hline Endowment $=100$ & 10 rounds & 10 rounds \\
\hline \multicolumn{3}{|l|}{ Initial prize $=40$} \\
\hline \multicolumn{3}{|l|}{ Second prize $=40$} \\
\hline \multicolumn{3}{|l|}{ Asymmetric-VCM } \\
\hline $\mathrm{MPCR}=\{0.9,0.1,0.1,0.1\}$ & $N=20$ subjects & $N=12$ subjects \\
\hline Endowment $=100$ & 10 rounds & 10 rounds \\
\hline \multicolumn{3}{|l|}{ Asymmetric-NPL } \\
\hline $\mathrm{MPCR}=\{0.9,0.1,0.1,0.1\}$ & $N=20$ subjects & $N=16$ subjects \\
\hline Endowment $=100$ & 10 rounds & 10 rounds \\
\hline \multicolumn{3}{|l|}{ Prize $=\{50,20,10\}$} \\
\hline \multicolumn{3}{|l|}{ Asymmetric-REB } \\
\hline $\mathrm{MPCR}=\{0.9,0.1,0.1,0.1\}$ & $N=20$ subjects & $N=16$ subjects \\
\hline Endowment $=100$ & 10 rounds & 10 rounds \\
\hline \multicolumn{3}{|l|}{ Prize $=80$} \\
\hline \multicolumn{3}{|l|}{ Asymmetric-TON } \\
\hline $\mathrm{MPCR}=\{0.9,0.1,0.1,0.1\}$ & $N=20$ subjects & $N=16$ subjects \\
\hline Endowment $=100$ & 10 rounds & 10 rounds \\
\hline \multicolumn{3}{|l|}{ Initial Prize $=40$} \\
\hline Second Prize $=40$ & & \\
\hline
\end{tabular}

Note: Cell entries provide the experimental design and parameters for each treatment. For example, in the SymmetricVCM treatment the MPCR $=0.30$ and the subjects were endowed with 100 tokens. In this treatment there was one session of 20 subjects that lasted for 10 rounds.

In such instances, our theory suggests that it is possible to improve upon the performance of a single-prize lottery using an appropriately designed tontine. Such a tontine will not only generate higher contribution levels for the charity in the short-run, it will also attract a larger number of donors which will aid the charity in future campaigns by expanding the size of the organization's warm list. 


\section{Experimental design and results}

We design an experiment to examine several of our theoretical predictions. Table 1 provides an experimental design summary. We begin with a control treatment that induces symmetric marginal per capita returns (MPCR's) across agents in a voluntary contribution mechanism (denoted Symmetric-VCM in Table 1). Our other VCM treatment introduces heterogeneous valuations for the public good, but holds constant the average MPCR (denoted AsymmetricVCM). We cross these treatments with comparable treatments: symmetric single-prize lottery (denoted Symmetric-SPL), asymmetric multiple-prize lottery (denoted Asymmetric-NPL), single stage endogenous rebate (denoted Symmetric-REB and Asymmetric-REB), and twostage tontine (Symmetric-TON and Asymmetric-TON) treatments, leading to a total of 8 treatments. $^{12}$

All treatments were conducted at the University of Maryland-College Park. The experiment consisted of multiple sessions held on separate days with different subjects. Each session consisted of two parts, the first to gather information on individual contribution decisions across the various treatments. The second part was included to gather information on individual risk postures. We describe, in turn, each part of the session.

\subsection{Part 1}

The first part of the experiment was designed to compare contribution levels across the symmetric single-prize lottery, the asymmetric multiple-prize lottery, two variants of a historical tontine, and the voluntary contribution mechanism. The voluntary contribution mechanism treatment and the single-prize lottery treatment followed the instructions from Morgan and Sefton (2000) to enable direct comparison. Table 1 summarizes the key features of our experimental design and the number of participants in each treatment. Subjects were recruited on campus at the University of Maryland - College Park using posters and emails that advertised subjects could "earn extra cash by participating in an experiment in economic decision-making." The same protocol was used to ensure that each session was run identically.

Each subject was seated at linked computer terminals that were used to transmit all decision and payoff information. All sessions were programmed using the software toolkit $z$-Tree developed by Fischbacher (1999). The sessions each consisted of 12 rounds, the first two being practice rounds that did not affect earnings. Once the individuals were seated and logged into the terminals, a set of instructions and a record sheet were distributed. Subjects were asked to follow along as the instructions (included in Appendix B and Appendix C) were read aloud.

At the beginning of each round subjects were randomly assigned to groups of four. Subjects were unaware of their partners' identities, but we aware that the groups changed every round. Each round the subjects were endowed with 100 tokens. Their task was simple: decide how many tokens to place in the group account and how many to place in their private account. After all subjects made their choice, the computer would inform them of the total number of tokens placed in their group account, the number of points from the group account and the private account, as well as any bonus points that were earned. The payoff for the round was determined by summing the points from the group account, points from the private account, and any bonus points received.

\footnotetext{
${ }^{12}$ Data for the Symmetric-SPL, Asymmetric-NPL, and VCM treatments are from Lange et al. (2007). Data for the remaining treatments are original to this study.
} 
The points for each round were determined as follows. For all sessions, subjects received 1 point for each token placed in their private account. In the four treatments with symmetric valuations for the public good, they were awarded 0.3 points for each token placed in the group account by themselves and the other members of their group. In the four treatments with asymmetric valuations for the public good, subjects were awarded either 0.9 or 0.1 points for each token placed in the group account. ${ }^{13}$ Additionally, each session had a different method for earning bonus points.

We follow Morgan and Sefton (2000) by adding the value of the prize ( 80 tokens) to the group account in the VCM. In the symmetric VCM session, all subjects therefore earned 24 bonus points; in the asymmetric VCM session, subjects received either 72 or 8 bonus points. These bonus points represent 80 tokens placed in the group accounts.

In the single-prize lottery sessions, group members competed for a lottery prize of 80 points. Each subject's chance of winning the prize was based on his or her contribution to the group account compared to the aggregate number of tokens placed in the group account by all group members. For the multiple-prize lottery sessions, group members competed for three lottery prizes of values 50, 20, and 10 points, respectively. As in the single-prize lottery, subjects' chances of winning the first prize were based on his or her share of group contributions. The three prizes were awarded in order of value, and without replacement, meaning that in each round 3 of the 4 group members would receive some bonus points.

For the single-stage rebate sessions, group members competed for an endogenously determined share of the 80 bonus points. Each subjects' share of this bonus was equal to his or her contribution to the group account compared to the aggregate number of token placed in the group account by all group members. Hence, any individual who contributed to the group account was guaranteed to receive some bonus points.

For the two-stage tontine sessions, group members competed for a share of 80 bonus points split evenly across two prizes: an initial allocation of 40 bonus points amongst all group members and a second allocation of 40 bonus points amongst two randomly selected group members. Each subjects' share of the initial bonus was equal to his or her contribution to the group account relative to the aggregate number of tokens placed in the group account. The remaining 40 bonus points were allocated similarly amongst two randomly determined group members. ${ }^{14}$

At the end of the experiment, one of the non-practice rounds was chosen at random to determine earnings. Subjects were paid $\$ 1.00$ for every 15 points earned in this randomly chosen round. They recorded their earnings for Part 1 of the session and added those to their earnings for Part 2 of the experiment to determine total earnings for the session.

\subsection{Part 2}

The second part of the session was designed to lend insights into subjects' risk postures and link those preferences to behavior in the public goods game described above. Attempting to

\footnotetext{
${ }^{13}$ In the asymmetric sessions, there was one agent in each group of four who had a valuation for the public account of 0.9 and three agents who had valuations of 0.1 for tokens placed in the group account. Individual valuations were held constant throughout the session, and each group of four had exactly one member with the high valuation and three members with the low valuation.

14 The two randomly selected group members were chosen by a computer using "survival" probabilities that were independent of contribution decisions and identical for each individual in the session. Thus, each individual had a $50 \%$ chance of being selected to compete for the additional bonus points.
} 
Table 2

Nash equilibrium predictions for risk neutral agents

\begin{tabular}{lllll}
\hline & Total group contributions & Individual donation & High value agents & Low value agents \\
\hline Symmetric-SPL & 85.7 tokens & 21.43 tokens & & \\
Symmetric-REB & 85.7 tokens & 21.43 tokens & & 8.5 tokens \\
Symmetric-TON & 71.4 tokens & 17.85 tokens & & 3.2 tokens \\
Asymmetric-NPL & 94.1 tokens & & 75.6 tokens & 7.1 tokens \\
Asymmetric-REB & 85.7 tokens & & 80.9 tokens & \\
Asymmetric-TON & 102.2 tokens & & & \\
\hline
\end{tabular}

Note: Cell entries provide the Nash equilibrium predictions for risk-neutral agents in our two lottery and four tontine treatments. For example, in the symmetric single-prize lottery (Symmetric-SPL) each agent is predicted to contribute 21.43 tokens to the public account.

measure risk postures in one game and applying them to more closely explore behavior in another is not novel to this study. Yet, as risk posture is not exogenously imposed on players (such as MPCR's are induced in the public goods game) an important caveat must be placed on the results from such an exercise.

In this part of the session, the low-payoff treatment of Holt and Laury (2002) was replicated with all values multiplied by a factor of four (see Appendix D for instructions). ${ }^{15}$ The treatment is based on ten choices between paired lotteries which are included in the Appendix. The payoff possibilities for Option A, $\$ 8.00$ or $\$ 6.40$, are much less variable than those for Option B, $\$ 15.40$ or $\$ 0.40$. The odds of winning the higher payoff for each of the options increase with each decision.

Upon completion of Part 1 of the session, instructions and a decision sheet were handed out. After the directions were read and questions were answered, the subjects were asked to complete their decision sheets by choosing either A or B for each of the ten decisions. The subjects were instructed that one of the decisions would be randomly selected ex post and used to determine their payoffs. After each subject completed his or her decision sheet, a monitor would approach the desk and randomly draw a card twice, once to select which of the ten decisions to use, and a second time to determine what the payoff was for the option chosen, A or B, for the particular decision selected.

After all the subjects' payoffs were determined, they combined their payoff from Part 1 with that of Part 2 to compute their final earnings. The final payoffs were then verified against the computer records, and subjects were paid privately in cash for their earnings. Each of the sessions lasted approximately $75 \mathrm{~min}$.

\subsection{Experimental results}

Our experimental design enables us to test a number of theoretical predictions regarding contribution levels. Table 2 summarizes the Nash equilibrium predictions for risk-neutral agents in our various lottery and tontine treatments. We craft the results summary by first pooling the data across subjects of all risk postures, but later explore the effects of risk preference on

\footnotetext{
15 The payoffs for the Holt and Laury experiment were multiplied by a factor of four so that the domain of earnings from this experiment $(\$ 0.40, \$ 15.40)$ would correspond with the domain of potential earnings from the public goods game $(\$ 1.20, \$ 29.33)$.
} 
Table 3

Mean contribution levels by treatment

\begin{tabular}{lcc}
\hline & All periods pooled & Final five periods only \\
\hline Symmetric REB & $35.59(28.8)$ & $32.7(27.2)$ \\
Symmetric TON & $39.96(27.13)$ & $39.52(27.34)$ \\
Symmetric VCM & $22.85(31.11)$ & $13.34(24.23)$ \\
Symmetric SPL & $42.65(32.82)$ & $40.29(32.16)$ \\
Asymmetric REB (All Agents Pooled) & $33.30(31.16)$ & $27.94(29.65)$ \\
Agents with MPCR $=0.9$ & $60.91(32.61)$ & $59.8(33.44)$ \\
Agents with MPCR $=0.1$ & $24.1(24.58)$ & $17.32(18.77)$ \\
Asymmetric TON (All Agents Pooled) & $35.46(29.81)$ & $33.54(29.85)$ \\
Agents with MPCR $=0.9$ & $61.28(27.05)$ & $60.96(27.23)$ \\
Agents with MPCR $=0.1$ & $26.86(25.43)$ & $24.4(24.71)$ \\
Asymmetric VCM (All Agents Pooled) & $25.4(29.9)$ & $20.59(28.73)$ \\
Agents with MPCR $=0.9$ & $50.85(32.77)$ & $48.13(32.3)$ \\
Agents with MPCR $=0.1$ & $16.92(23.43)$ & $11.41(20.51)$ \\
Asymmetric NPL (All Agents Pooled) & $41.01(35.21)$ & $38.88(34.29)$ \\
Agents with MPCR $=0.9$ & $64.16(38.33)$ & $64.62(38.79)$ \\
Agents with MPCR $=0.1$ & $33.3(30.49)$ & $30.30(27.93)$ \\
\hline
\end{tabular}

Note: Cell entries provide the mean and standard deviation for each treatment. For example, in the VCM-symmetric treatment the average token contribution was 22.845 with a standard deviation of 31.1 tokens.

contribution schedules. This approach permits a direct comparison of our data with results from the voluminous public goods literature.

Our first hypothesis is that the lottery and tontine treatments introduce private incentives that generate greater contributions than a voluntary contribution mechanism. Table 3 provides mean

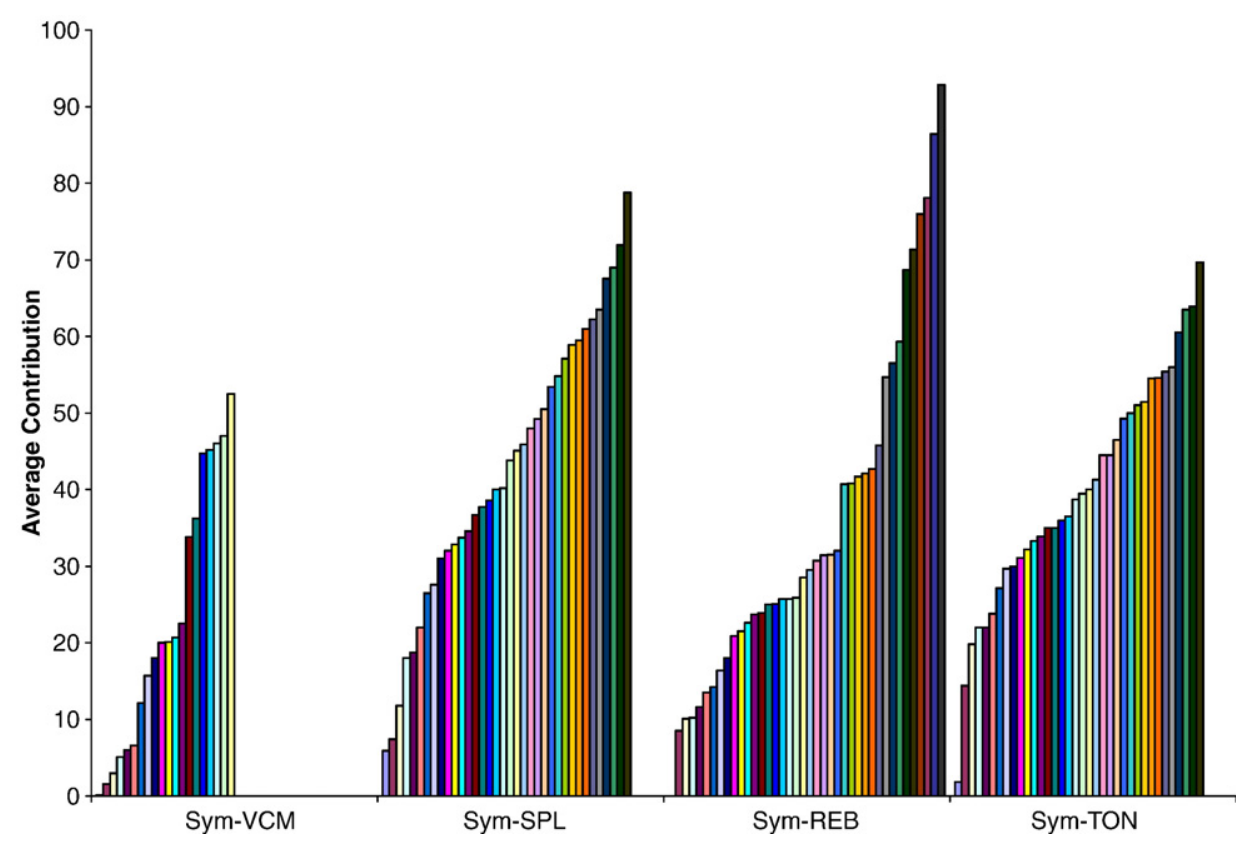

Fig. 1. Mean contribution levels (symmetric sessions only). 


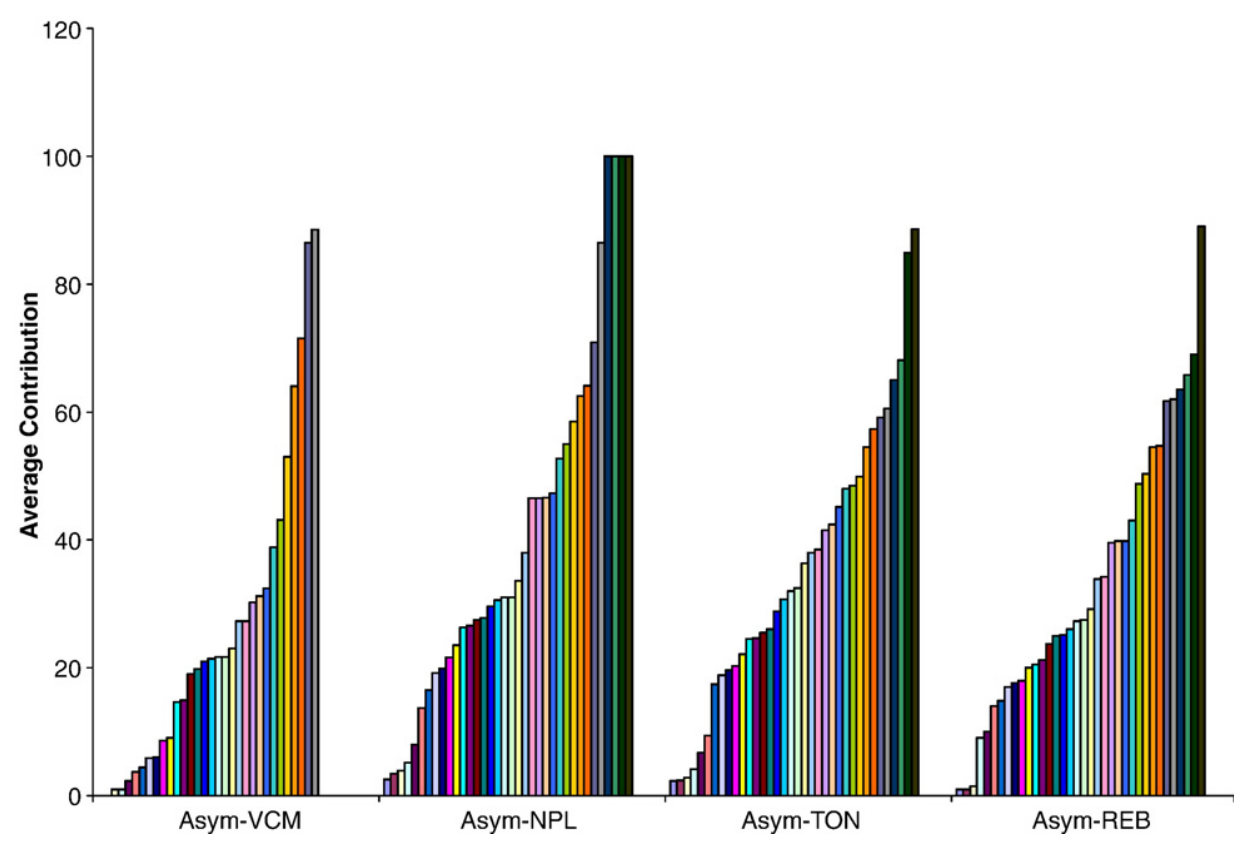

Fig. 2. Mean contribution levels (asymmetric sessions only).

contribution levels for our experimental data, and Figs. 1 and 2 provide a graphical depiction of the data. As can be seen in the table and the figures, contribution levels in the lottery and tontine treatments are greater than those in either VCM treatment.

Measured over all treatments, contribution levels in the symmetric VCM and SPL treatments were 22.85 and 42.65 tokens, respectively, a difference that is statistically significant at the $p<0.01$ level using a Mann-Whitney test. ${ }^{16}$ Mean contribution levels in the symmetric rebate and two-stage tontine treatment were 35.59 and 39.96 tokens. These means are significantly different from the VCM average at the $p<0.05$ level using a Mann-Whitney test.

For the asymmetric sessions, we observe similar data patterns: mean contribution levels in the asymmetric VCM (NPL) treatment were 25.4 (41) tokens. Mean contributions in the asymmetric TON (REB) treatments were 35.46 tokens (33.3 tokens), respectively. The difference in mean contributions between both the NPL and 2-Stage tontine (TON) and the VCM treatment are statistically significant at the $p<0.05$ level. The difference in mean contribution levels between the REB treatment and the VCM treatment is statistically significant at the $p<0.10$ level. These results also hold if we restrict attention to the final five periods of play. Combined, these data generate our first result:

Result 1. Linking charitable donations with the provision of a private prize generates greater contributions than a VCM. The dominance of such mechanisms hold whether contributions affect

\footnotetext{
${ }^{16}$ The unit of observation for the Mann-Whitney test is the average contribution level for each agent across the ten rounds. Thus, each subject provides one data point in these tests.
} 
the probability an agent wins a prize of given value (as in charitable lotteries) or the proportion of a fixed return the agent receives (as in the tontine).

The first part of Result 1 is similar to the findings in Morgan and Sefton (2000), Dale (2004) and Landry et al. (2006), whereas we are unaware of any antecedent to the second part of Result 1.

\subsection{Comparing tontines with single and multiple period payouts}

Our theoretical model suggests that the optimal tontine for agents with identical preferences for a public good consists of a degenerate payment schedule wherein all agents receive a fixed "prize" amount in the first stage equal to a percentage of their total contribution. For symmetric agents, any tontine that allocates payments of a fixed amount across multiple stages generates strictly lower contributions to the public good than this optimal rebate scheme. In our experimental setting, we would thus expect contribution levels in the symmetric REB treatment to exceed those realized in the symmetric two stage tontine (TON) treatment.

In contrast, our theoretical model shows that the optimal tontine allocates payments across multiple stages when individual preferences for the public good are sufficiently heterogeneous. Under the parameter values employed in our asymmetric sessions, the optimal tontine splits payments into different prizes. Hence, as suggested in Table 2, we would expect contribution levels in the asymmetric two-stage tontine to exceed those realized in the asymmetric REB treatment.

Table 3 provides mean contribution levels for both the symmetric and asymmetric tontine sessions. Averaged over all periods, mean contribution levels in the asymmetric TON sessions were 35.46 tokens - approximately 2.16 tokens greater than those observed in the asymmetric REB treatment (33.30 tokens). Restricting the analysis to the final five periods of the experiment, the difference in average contribution levels between the asymmetric TON and REB treatments is 5.6 tokens (33.54 tokens versus 27.94 tokens). While the former difference is not statistically significant at any meaningful level, the latter difference is significant at the $p<0.10$ level using a Mann-Whitney test.

We observe similar data patterns in our symmetric tontine sessions. Averaged across all (the final five) periods, mean contributions in the symmetric TON sessions were 39.96 tokens (39.52 tokens). For the symmetric REB sessions, mean contributions for all (the final five) periods were 35.59 tokens (32.7 tokens). While the overall difference of 4.37 tokens is not statistically significant at any meaningful level, the 6.82 token difference between the treatments for the final five periods is significant at the $p<0.10$ level. Combined these data lead to our second result:

Result 2. Contributions in a tontine that allocates payments over two-stages weakly dominate those of a tontine that allocates the total prize to all agents relative to their contributions. This weak dominance holds whether agents have symmetric or asymmetric values for the public good.

We thus find mixed support for our theory. The dominance of the 2-Stage tontine (TON) in cases of asymmetric preferences is consistent with Proposition 5 of our theoretical model, but the finding that contributions in the symmetric case are greater in the TON than in the REB is at odds with Proposition 1.

\subsection{Tontines, lotteries, and risk-aversion}

The above analysis follows the spirit of the literature in that all agents are pooled and a series of hypotheses are tested jointly-in this case, risk assumptions are met and direction of treatment 
Table 4

Mean contribution levels by risk preference

\begin{tabular}{lll}
\hline & Risk loving and risk neutral agents & Highly risk averse agents \\
\hline Symmetric REB & $20(25.05) N=7$ & $35.35(27.81) N=21$ \\
Symmetric TON & $37.55(26.5) N=11$ & $37.38(26.58) N=16$ \\
Symmetric VCM & $29.27(31.17) N=7$ & $18.9(29.11) N=9$ \\
Symmetric SPL & $49.39(33.56) N=7$ & $40.24(32.31) N=25$ \\
Asymmetric REB (All agents pooled) & $29.84(35.4) N=9$ & $31.46(26.92) N=21$ \\
Agents with MPCR $=0.9$ & $64.65(38.38)$ & $53.64(28.07)$ \\
Agents with MPCR $=0.1$ & $19.9(27.56)$ & $24.53(22.51)$ \\
Asymmetric TON (All agents pooled) & $40.58(29.59) N=10$ & $35.31(29.69) N=22$ \\
Agents with MPCR $=0.9$ & $58.6(24.96)$ & $64.15(30.24)$ \\
Agents with MPCR $=0.1$ & $28.57(25.19)$ & $28.91(25.55)$ \\
Asymmetric VCM (All agents pooled) & $23.95(26.07) N=8$ & $28.86(33.05) N=18$ \\
Agents with MPCR $=0.9$ & $43.73(22.71)$ & $55.12(37.11)$ \\
Agents with MPCR $=0.1$ & $12.08(20.17)$ & $18.75(24.94)$ \\
Asymmetric NPL (All agents pooled) & $49.26(36.52) \mathrm{N}=12$ & $31.68(30.60) \mathrm{N}=17$ \\
Agents with MPCR $=0.9$ & $76(30.7)$ & $56.67(35.46)$ \\
Agents with MPCR $=0.1$ & $35.89(31.63)$ & $26.33(26.7)$ \\
\hline
\end{tabular}

Note: Cell entries provide the average contribution levels and associated standard deviations by revealed risk posture for our experimental treatments.

effects are tested. We can examine our data at a level deeper based on our theoretical predictions and subjects' revealed risk preference in Part II of our experiment. Our categorizations of risk preference are based on the number of safe choices "Option A" selected by the agent in the Holt/ Laury experimental design. Under the basic Holt/Laury design, an increase in the number of safe alternatives selected by an agent implies an increase in her implied risk preference.

Our theory provides four testable implications of risk-aversion on contributions in our experimental treatments: (i) contributions in the rebate tontine are independent of individual risk preference, (ii) contributions in the lottery treatments are strictly decreasing in the level of risk-aversion, (iii) contributions in the rebate tontine dominate those observed in any lottery when agents are risk-averse and have symmetric preferences for the public good, and (iv) independent of risk preference, contributions in our 2-stage tontine dominate those observed in our multiple-prize lottery when agents have asymmetric preferences for the public good. Table 4 summarizes mean contribution levels across our experimental treatments for agents classified as risk-loving/risk-neutral and those classified as highly risk-averse in the Holt/Laury experiment. ${ }^{17}$

Perusal of the table provides a number of insights consistent with our theoretical predictions. First, mean contributions for agents classified as risk-loving/risk-neutral in the symmetric, singleprize lottery are approximately $23 \%$ greater than those for agents classified as highly risk-averse (49.39 tokens versus 40.24 tokens). We observe a similar relationship between risk preference and contributions in the asymmetric, multi-prize lottery treatments: the mean contribution level for risk-loving/risk-neutral agents (49.26 tokens) is approximately 55.6\% greater than the level for

\footnotetext{
${ }^{17}$ This was done as a first attempt to place agents in cells that our theory would predict would lead to behavioral differences. In this case, we define "Highly" risk-averse agents as those who select the safe lottery (Lottery A) in at least 6 choice occasions. This corresponds to an implied CARA preference of approximately 0.08 or higher. Agents who are risk-loving/neutral play the safe lottery 4 or fewer times. Thus, the omitted group (those who select the safe lottery 5 times) has an implied CARA preference of 0.03 .
} 
Table 5

Individual contribution decisions — symmetric sessions

\begin{tabular}{lll}
\hline & Tokens contributed model A & Tokens contributed model B \\
\hline Constant - symmetric VCM is baseline & $22.84^{* *}(4.18)$ & $22.84^{* *}(4.16)$ \\
Symmetric rebate treatment & $12.75^{* *}(5.11)$ & $11.92(11.80)$ \\
Symmetric 2 - stage tontine treatment & $17.11^{* *}(5.21)$ & $14.61(11.83)$ \\
Single-prize lottery treatment & $19.80^{* *}(5.21)$ & $31.24^{* *}(11.97)$ \\
HL count in symmetric rebate treatment & & $0.14(1.79)$ \\
HL count in symmetric 2-stage tontine treatment & & $0.47(2.01)$ \\
HL count in single-prize lottery treatment & & $-2.09^{*}(1.27)$ \\
Number of observations & 1320 & 1320 \\
Number of agents & 132 & 132 \\
Individual random effects & Yes & Yes \\
Log likelihood & -6212.2 & -6211.6 \\
\hline
\end{tabular}

** Denotes statistical significance at the $p<0.05$ level.

* Denotes statistical significance at the $p<0.10$ level.

Note: Cell entries provide parameter estimates from a linear random effects regression of individual contribution decisions. Standard errors are in parentheses. Importantly treatment indicators in Model 2 represent the predicted contribution levels for an infinitely risk-loving agent - i.e., an agent with an HL count of zero - whereas the treatment indicators in Model 1 are pooled over agents of all risk posture and represent the predicted contribution level of the representative agent in the associated treatment.

highly risk-averse agents (31.68 tokens). Second, in both the symmetric and asymmetric REB sessions, mean contribution levels for agents classified as highly-risk averse are only slightly greater than those observed for risk-loving/risk-neutral counterparts suggesting risk posture has no discernable impact on contribution decisions. ${ }^{18}$ Finally, for agents classified as highly riskaverse, contributions are approximately $11.5 \%$ greater in the asymmetric 2 -stage tontine treatment than the asymmetric multi-prize lottery (35.31 tokens versus 31.68 tokens).

Yet, Table 4 highlights other insights that are inconsistent with our theoretical predictions. First, the average contribution for risk-averse agents in the symmetric rebate treatment is approximately $13.8 \%$ less than that for risk-averse counterparts in the symmetric single-prize lottery. Second, independent of risk posture, average contributions in the symmetric rebate treatment are less than those realized in the symmetric 2-stage tontine. Finally, average contributions for risk-neutral agents in the asymmetric 2 -stage tontine are approximately $21.4 \%$ less ( 40.58 versus 49.26 tokens) than those for risk-neutral counterparts in the asymmetric multi-prize lottery.

To augment these unconditional insights, we estimate a linear random effects regression model of individual contribution levels as: ${ }^{19}$

$$
C_{i t}=v\left(Z_{i t}\right)+\varepsilon_{i t},
$$

where $C_{i t}$ is the contribution level of the $i$ th agent in period $t . Z_{i t}$ includes treatment dummy variables, the interaction of the treatment dummies with an indicator for agents with a high

\footnotetext{
18 Yet, there is an approximate 15 token difference in the contribution levels of risk-neutral and risk-averse agents in our symmetric rebate sessions. This difference is driven predominantly by three risk-neutral agents in this treatment that free-ride in at least seven of the ten rounds. If we exclude these individuals (or control for individual level heterogeneities as in our regression analysis) there are no discernable differences in contribution levels across risk-neutral and risk-averse counterparts.

${ }^{19}$ In the regression models we use the number of safe choices to indicate individual risk preference. Results are qualitatively similar if we run the model using three categorical variables for risk-loving/risk-neutral agents (CARA less than or equal to 0), risk-averse (CARA 0.01-0.079), and highly risk-averse (CARA $>0.079$ ).
} 
Table 6

Prediction contribution levels — risk averse agents

\begin{tabular}{llll}
\hline & Rebate tontine & Single-prize lottery & 2-stage tontine \\
\hline Holt-Laury count $=4$ & $35.32[26.38-44.26]$ & $45.73[37.40-54.05]$ & $39.35[31.45-47.24]$ \\
Holt-Laury count $=5$ & $35.46[28.80-42.12]$ & $43.63[37.29-49.98]$ & $39.82[33.65-45.99]$ \\
Holt-Laury count $=6$ & $35.60[29.83-41.36]$ & $41.54[35.14-47.95]$ & $40.30[33.59-47.01]$ \\
Holt-Laury count $=7$ & $35.74[28.9-42.58]$ & $39.45[30.98-47.92]$ & $40.77[31.66-49.89]$ \\
Holt-Laury count $=8$ & $35.88[26.66-45.09]$ & $37.36[25.86-48.86]$ & $41.24[28.90-53.59]$ \\
Holt-Laury count $=9$ & $36.02[23.87-48.17]$ & $35.27[20.35-50.19]$ & $41.72[25.82-57.62]$ \\
Holt-Laury count $=10$ & $36.16[20.82-51.49]$ & $33.18[14.66-51.70]$ & $42.19[22.59-61.80]$ \\
\hline
\end{tabular}

Note: Cell entries provide the predicted contribution level and $95 \%$ confidence interval (in brackets). Cell entries can be read as follows, an agent with a Holt-Laury count of six in our Rebate Tontine treatment is predicted to contribute 35.6 tokens to the public account. The associated $95 \%$ confidence interval for such an agent is 29.83 to 41.36 tokens.

$(\mathrm{MPCR}=0.9)$ or low $(\mathrm{MPCR}=0.1)$ valuation for the public good, and the interaction of the treatment indicators with the number of safe alternatives agent $i$ selected in the Holt-Laury experiment (a proxy for individual risk preference). We specify the error structure as $\varepsilon_{i t}=\alpha_{i}+u_{i t}$ where the random effects $\alpha_{i}$ capture important heterogeneity across agents that would be left uncontrolled in a standard cross-sectional model.

Table 5 provides results for this model across two different specifications for our symmetric treatments. Results from these models provide mixed support for our theory. First, as noted in column 1, linking contributions with the provision of a private prize generates greater contribution levels than a voluntary contribution mechanism; average contributions in the rebate, 2-stage tontine, and single-prize lottery treatment are significantly greater than in our baseline VCM at the $p<0.05$ level. Further, contributions in the rebate treatment are independent of risk preference: the estimated coefficient on the interaction of risk preference and the indicator for the optimal rebate in column 2 is not significant at any meaningful level. However, lottery contributions are decreasing in the level of individual risk-aversion: the estimated coefficient on the interaction of risk preference and the indicator for the single-prize lottery is negative and significant at the $p<0.10$ level. Thus, while the predicted contributions for an infinitely riskloving individual are approximately 19.32 tokens greater in the SPL treatment than in the REB treatment, this difference falls by approximately 2.23 tokens with every one unit increase in our proxy for individual risk posture (the Holt-Laury count).

One insight garnered from Table 5 not predicted by our theory is the apparent superiority of the single-prize lottery as a fundraising mechanism. As noted in column 1, average contributions in the SPL treatment are approximately 7 tokens greater than those observed in the symmetric rebate treatment. We observe similar insights when we include individual specific controls for risk posture in column 2. Indeed, contributions in the symmetric single-prize lottery are greater than those in the symmetric rebate treatment for any agent who selects the safe option on eight or fewer choice rows in the Holt-Laury experiment. ${ }^{20}$ Combined, these insights lead to our third result:

\footnotetext{
${ }^{20}$ This insight can be obtained directly from examining Table 6, which presents predicted contribution levels and associated $95 \%$ confidence intervals across the various symmetric treatments. Cell entries in Table 6 are calculated using parameter estimates from Column 2 of Table 5 and suggest that any agent with an HL count less than 8.67 contributes more in the SPL than the REB treatment. In economic terms, this implies that any agent with a CARA preference of approximately 0.2 or less will contribute more in the SPL.
} 
Result 3. Risk posture has a critical influence on the relative performance of charitable lotteries and tontines. Yet contributions in the single-prize lottery weakly dominate those in the symmetric rebate for all but extreme levels of risk-aversion.

Data from our symmetric sessions thus provide mixed support for the theoretical model in Section 3. The first part of this result is consistent with Proposition 3, whereas the second part contradicts the predicted superiority of the rebate mechanism for all levels of risk-aversion. However, since the $95 \%$ confidence intervals in Table 6 overlap for all levels considered, we are unable to make definitive statements regarding the dominance of any particular fundraising instrument.

Table 7 provides a similar set of regression models using data from our asymmetric treatments. Because marginal values for the public good now differ, we include controls for those in the regression model. Perusal of the data in Table 7 highlights a number of interesting insights. First, as illustrated in column 1, average contribution levels for both low and high value agents are greater under the 2-stage tontine than the rebate treatment. This is consistent with our theoretical prediction that the optimal tontine for agents with asymmetric preferences lets a randomly drawn subset of players compete for part of the total prize. Furthermore, contributions in the REB treatment are independent of risk posture consistent with our theoretical model.

One departure from our theoretical predictions is the apparent superiority of the multi-prize lottery relative to the 2-stage tontine for high value agents. As shown from estimation of Model A,

Table 7

Individual contribution decisions - Asymmetric sessions

\begin{tabular}{lll}
\hline & Tokens contributed Model A & Tokens contributed Model B \\
\hline Model constant — low value agent in VCM is baseline & $16.92^{* *}(3.89)$ & $16.92^{* *}(3.84)$ \\
High value agent in VCM treatment & $33.93^{* *}(7.79)$ & $33.93^{* *}(7.68)$ \\
Low value agent in rebate treatment & $7.18(5.36)$ & $11.44(12.26)$ \\
High value agent in rebate treatment & $43.99^{* *}(7.46)$ & $68.66^{* *}(28.13)$ \\
Low value agent in 2-stage tontine & $9.94^{*}(5.36)$ & $6.09(13.27)$ \\
High value agent in 2-stage tontine & $44.36^{* *}(7.46)$ & $46.33^{* *}(17.73)$ \\
Low value agent in multi-prize lottery & $16.38^{* *}(5.36)$ & $25.71^{*}(14.55)$ \\
High value agent in multi-prize lottery & $47.24^{* *}(7.46)$ & $72.29^{* *}(17.07)$ \\
HL count of low value agent in rebate treatment & & $-0.78(2.01)$ \\
HL count of high value agent in rebate treatment & & $-4.93(5.43)$ \\
HL count of low value agent in 2-stage tontine & & $0.65(2.05)$ \\
HL count of high value agent in 2-stage tontine & & $-0.43(3.54)$ \\
HL count of low value agent in multi-prize lottery & & $-1.78(2.58)$ \\
HL count of high value agent in multi-prize lottery & & $-5.78^{*}(3.55)$ \\
Number of observations & 1400 & 1400 \\
Number of agents & 140 & 140 \\
Individual random effects & Yes & Yes \\
Log likelihood & -6427.1 & -6424.9 \\
\hline
\end{tabular}

** Denotes statistical significance at the $p<0.05$ level.

* Denotes statistical significance at the $p<0.10$ level.

Note: Cell entries provide parameter estimates from a linear random effects regression of individual contribution decisions. Standard errors are in parentheses. Importantly treatment indicators in Model 2 represent the predicted contribution levels for an infinitely risk-loving agent - i.e., an agent with an HL count of zero - whereas the treatment indicators in Model 1 are pooled over agents of all risk posture and represent the predicted contribution level of the representative agent in the associated treatment. 
such agents contribute an average of approximately 2.88 tokens more in the multiple prize lottery treatment than their counterparts contribute in the tontine treatment. Yet, such differences depend critically on individual risk preference, as revealed in Model B, where lottery contributions are found to be strictly declining in individual risk posture. In this model, the estimated coefficient on the interaction of the proxy for risk preference and the indicator for a high valued agent in the multi-prize lottery is negative and statistically significant at the $p<0.10$ level. Thus, while an infinitely risk-loving high value agent would contribute approximately 26 more tokens in the multiple-prize lottery than in the 2-stage tontine, this difference falls by 5.35 tokens for every unit increase in our proxy for individual risk posture. In fact, as shown in Table 8, risk-averse agents are predicted to contribute more in the 2-stage tontine treatment than would a counterpart agent in the multi-prize lottery. Combined, this leads to a fourth result:

Result 4. Contributions in the asymmetric 2-stage tontine weakly dominate those for the asymmetric rebate tontine for both high and low value agents. Contributions in the asymmetric 2-stage tontine weakly dominate those for the asymmetric multi-prize lottery when agents are risk-averse.

The first part of the result is consistent with the implications of proposition 5, which suggests that the optimal tontine for asymmetric individuals splits prize payments and selects randomly a subgroup of players to compete over part of the prize. The second part of the result provides mixed support for Proposition 6 which predicts the superiority of the 2-stage tontine independent of risk posture.

\subsection{Tontines, lotteries, and net public good provision}

Thus far we have focused on individual contributions across the various treatments. A further prediction of our theory is that both tontines and lotteries generate contributions in excess of total prize payments and can increase the total public good provision. Recall that in our lottery and tontine treatments the exogenous prize amount was 80 tokens. Accordingly, we must account for these prize values by subtracting 80 tokens from total group contributions in these treatments. Following Morgan and Sefton (2000), we provide Table 9 which summarizes net public good provision and the associated $95 \%$ confidence interval across our various treatments for

Table 8

Predicted contribution levels — risk neutral agents

\begin{tabular}{ccccc}
\hline & Holt-Laury count $=4$ & Holt-Laury count $=5$ & Holt-Laury count=6 & Holt-Laury count=7 \\
\hline $\begin{array}{c}\text { Low value agent in } \\
\text { 2-stage tontine }\end{array}$ & $25.61[15.09-36.12]$ & $26.26[18.24-34.27]$ & $26.91[19.81-34.01]$ & $27.56[19.25-35.87]$ \\
$\begin{array}{c}\text { Low value agent in } \\
\text { multi-prize lottery }\end{array}$ & $35.53[26.00-45.06]$ & $33.76[26.54-40.98]$ & $31.99[23.96-40.01]$ & $30.21[18.1-41.52]$ \\
$\begin{array}{c}\text { High value agent in } \\
\text { 2-stage tontine }\end{array}$ & $61.52[48.64-74.39]$ & $61.08[48.42-73.76]$ & $60.65[44.79-76.51]$ & $60.22[39.28-81.17]$ \\
$\begin{array}{c}\text { High value agent in } \\
\text { multi-prize lottery }\end{array}$ & $66.08[53.58-78.59]$ & $60.30[47.16-73.44]$ & $54.53[37.61-71.43]$ & $48.74[26.46-70.01]$ \\
\hline
\end{tabular}

Note: Cell entries provide predicted contribution levels for an agent with a given valuation (high or low) for the public good and a given risk proxy. The associated $95 \%$ confidence interval for the prediction is in brackets. 
Table 9

Net public good provision - final round only

\begin{tabular}{lll}
\hline & Net provision & Difference from VCM \\
\hline Symmetric sessions & $59.0[14.6-103.4]$ & \\
VCM & $66.4[9.1-123.8]$ & $7.4(0.58)$ \\
Single-prize lottery & $25.2[6.9-43.5]$ & $-23.8(0.12)$ \\
Rebate & $56.3[19.9-92.7]$ & $-2.7(0.46)$ \\
2-stage tontine & & \\
& & $1.7(0.54)$ \\
Asymmetric sessions & $75.4[34.4-116.3]$ & $-43.2(0.03)$ \\
VCM & $77.1[44.7-109.5]$ & $-49.1(0.02)$ \\
Multiple-prize lottery & $32.2[0.3-64.1]$ & \\
Rebate & $26.3[0.4-52.3]$ & \\
2-stage tontine &
\end{tabular}

Note: Cell entries in Column 1 provide the average net provision level of the public good in round ten for each of our experimental treatments. The associated $95 \%$ confidence intervals are in brackets. Column 2 provides the difference in average provision levels between the associated row treatment and the VCM treatment. The $p$-value for a one-sided Wilcoxon Rank-Sum test that the row value is greater than the net provision level in the VCM treatments is given in parentheses.

the final round of play. We also provide results from a Wilcoxon Rank-Sum test on whether net public good provision is larger in the respective lottery and tontine treatments than the VCM treatments.

Data in Table 9 provide mixed support for our theoretical model: both tontines and lotteries generate contributions in excess of total prize payments. Further, the data highlight the power of the lottery mechanism: in both comparisons the data indicate that lotteries provide greater levels of the public good than the comparable VCM. Yet, this enthusiasm should be tempered, as the noisiness of the data renders all statistical tests insignificant. These results are in line with those in Morgan and Sefton (2000), though they do find some marginal significance. However, Table 9 highlights a potential caveat concerning the superiority of tontines as a fund-raising mechanism: net public good provision in our various tontine treatments is less than that observed in a comparable VCM with these differences being statistically significant in our asymmetric sessions. Yet, given that the tontine is able to generate greater levels of participation than the VCM, fundraisers might well accept this short-run revenue tradeoff.

\section{Concluding remarks}

This article provides a theoretical exploration of tontines as a fundraising instrument. Even though historically tontines have been a popular method of financing public goods - the name "tontine" remains prominently displayed on several publicly funded projects around the worldlittle is known about their potential benefits when applying their structure to provide incentives for voluntary giving.

In this study, we characterize a class of fundraising mechanisms inspired by historical tontines. By deriving the optimal tontine and formally linking the tontine to a popular modern fundraising scheme used by both government and charitable fundraisers - lotteries - we are able to show the equivalence of optimal tontines and single-prize lotteries for symmetric and risk-neutral agents. Upon relaxing the assumption of risk-neutrality and allowing for risk-aversion in a model with 
symmetric agents, we are able to show that contributions under the optimal tontine strictly dominate contributions raised under any lottery type. Further, the design of an optimal tontine is independent of underlying risk posture and generates contributions that weakly dominate those of any lottery.

We then extend the model to consider a set of risk-neutral agents with asymmetric valuations for the public good. Insights from this model are used to characterize situations when a tontine that awards prizes to a randomly determined subset of agents can yield higher contribution levels than the optimal lottery. Further, we show how the chance of being among the few competing players in such a multi-stage tontine can elicit contributions from agents who would not participate in the optimal lottery. Thus, if a fundraiser seeks to collect names of potential contributors for future fundraising drives, the tontine has an additional "hidden" advantage in that it increases participation rates.

We test our theory using a series of laboratory treatments and find evidence in favor of many of our theoretical predictions. Perhaps most importantly, gross contributions in both the rebate and the two-stage tontine treatments dominate those of the VCM, and are sufficient to cover total prize payments. Moreover, we find that risk posture and asymmetries in underlying marginal valuations for the public good are critical components determining the optimal fundraising instrument amongst the various forms of charitable lotteries and tontines considered in our experiment. In this spirit, our results add to the growing literature on the demand side of charitable fundraising and the private provision of public goods.

\section{Appendix A. Proofs}

Proof of Proposition 1. For any tontine, the equilibrium is given by the first order condition (2) for the set of participating players. We can rewrite Eq. (2) as follows:

$$
\begin{aligned}
0 & =\sum_{S=\left(S_{1}, \ldots, S_{T}\right) \in 2^{\Omega \times T}} \pi(S) u_{i}{ }^{\prime}(\bullet)\left[-1+h^{\prime}(\bullet)+\sum_{t=1}^{T} P_{t} \frac{B\left(S_{t}\right)-b_{i}}{B\left(S_{t}\right) b_{i}} \frac{b_{i}}{B\left(S_{t}\right)} 1_{\left[i \in S_{t}\right]}\right] \\
& \leq \sum_{S=\left(S_{1}, \ldots, S_{T}\right) \in 2^{\Omega \times T}} \pi(S) u_{i}{ }^{\prime}(\bullet)\left[-1+h^{\prime}(\bullet)+\frac{B-b_{i}}{B b_{i}} \sum_{t=1}^{T} P_{t} \frac{b_{i}}{B\left(S_{t}\right)} 1_{\left[i \in S_{t}\right]}\right] \\
& =\sum_{S=\left(S_{1}, \ldots, S_{T}\right) \in 2^{\Omega \times T}} \pi(S) u_{i}{ }^{\prime}\left(w-b_{i}+h(\bullet)+P_{i}(S)\right)\left[-1+h^{\prime}(\bullet)+\frac{B-b_{i}}{B b_{i}} P_{i}(S)\right] \\
\leq & \sum_{S=\left(S_{1}, \ldots, S_{T}\right) \in 2^{\Omega \times T}} \pi(S) u_{i}{ }^{\prime}\left(w-b_{i}+h(\bullet)+P_{i}(S)\right) \\
& \times\left[-1+h^{\prime}(\bullet)+\frac{B-b_{i}}{B b_{i}} \sum_{S=\left(S_{1}, \ldots, S_{T}\right) \in 2^{\Omega \times T}} \pi(S) P_{i}(S)\right]
\end{aligned}
$$

where the last inequality follows from $u_{i}^{\prime \prime}(\bullet) \leq 0$. Therefore, it follows that

$$
\sum_{S=\left(S_{1}, \ldots, S_{T}\right) \in 2^{\Omega \times T}} \pi(S) P_{i}(S) \geq\left(1-h^{\prime}(\bullet)\right) \frac{B b_{i}}{B-b_{i}}
$$


Since an optimal tontine must distribute all the prize money, summing over all participating players gives

$$
P \geq\left(1-h^{\prime}(\bullet)\right) \sum_{i} \frac{B b_{i}}{B-b_{i}} \geq\left(1-h^{\prime}(\bullet)\right) \frac{B \sum_{i} b_{i}}{B-(1 / n) \sum_{i} b_{i}}
$$

Here the last inequality follows from the convexity of $\frac{B b_{i}}{B-b_{i}}$ in $b_{i}$. We obtain

$$
B \leq \frac{1}{1-h^{\prime}(\bullet)} \frac{n-1}{n} P
$$

Comparing Eq. (A3) and condition (4), we immediately see that the pure rebate scheme maximizes the contribution to the tontine.

Proof of Proposition 4. Since a player can only win part of a prize if his or her contributions are positive, a player facing opponents with zero contributions could potentially choose an arbitrarily small but positive contribution level to secure the total amount distributed among this set of players. To deal with this case, we assume to the contrary of the claim of Proposition 4 that there is a set $S_{t}$ of $k_{t}$ players with $B\left(S_{t}\right)<\varepsilon$ for all $\varepsilon>0$. Consider the agent $i \in S_{t}$ with the minimal contribution. Then, the first order condition of this agent is given by

$$
\begin{gathered}
\sum_{S=\left(S_{1}, \ldots, S_{T}\right) \in 2^{\Omega \times T}} \pi(S) u_{i}{ }^{\prime}(\bullet)\left[-1+h_{i}{ }^{\prime}(\bullet)+\frac{\partial}{\partial b_{i}} \sum_{l=1}^{T} P_{l} \frac{b_{i}}{B\left(S_{l}\right)} 1_{\left[i \in S_{t}\right]}\right] \\
\geq \pi\left(S_{t}, S_{-t}\right) u_{i}{ }^{\prime}(\bullet)\left[-1+h_{i}{ }^{\prime}(\bullet)+P_{t} \frac{B\left(S_{t}\right)-b_{i}}{B\left(S_{t}\right)^{2}}\right] \\
\geq \pi\left(S_{t}, S_{-t}\right) u_{i}{ }^{\prime}(\bullet)\left[-1+h_{i}{ }^{\prime}(\bullet)+P_{t} \frac{B\left(S_{t}\right)-B\left(S_{t}\right) / k_{t}}{B\left(S_{t}\right)^{2}}\right] \\
\geq \pi\left(S_{t}, S_{-t}\right) u_{i}{ }^{\prime}(\bullet)\left[-1+h_{i}{ }^{\prime}(\bullet)+P_{t} \frac{k_{t}-1}{\varepsilon k_{t}}\right]
\end{gathered}
$$

which is larger than zero for small $\varepsilon$, implying a contradiction to the assumption. It follows that we have an interior solution $b_{i}>0$ for at least one $i \in S_{t}$.

Proof of Proposition 5. We analyze the tontine given by condition (5) with $P_{t}=0$ for $t=2, \ldots n-2$, $\left.P_{n-1}=\varepsilon, P_{1}=P-\varepsilon\right)$. With Proposition 4 , a set $\Omega_{\varepsilon}$ of $k \geq n-1$ agents contributes for $\varepsilon>0$. Let us define $\Omega_{1}$ as the set of players who contribute for arbitrarily small $\varepsilon>0$ but not for $\varepsilon=0$, similarly $k_{1}=\# \Omega_{1}$. The first-order conditions (1) can be rewritten as:

$$
1-h_{i}{ }^{\prime}(B-P)=(P-\varepsilon) \frac{B-b_{i}}{B^{2}}+\frac{2 \varepsilon}{n(n-1)} \sum_{j \in \Omega_{\ell} \backslash i} \frac{b_{j}}{\left(b_{i}+b_{j}\right)^{2}}
$$


We study the derivative of $B$ with respect to $\varepsilon$ at $\varepsilon=0$. For $i \in \Omega_{0}$, differentiation of Eq. (A4) yields

$$
\begin{aligned}
-h_{i}^{\prime \prime}(\bullet) B^{\prime}= & -\frac{B-b_{i}}{B^{2}}+\frac{2}{n(n-1)} \sum_{j \in \Omega_{0} \backslash i} \frac{b_{j}}{\left(b_{i}+b_{j}\right)^{2}} \\
& +P \frac{B\left(B^{\prime}-b_{i}{ }^{\prime}\right)-2 B^{\prime}\left(B-b_{i}\right)}{B^{3}} B B^{\prime}\left[\sum_{i \in \Omega_{0}}-h_{i}^{\prime \prime}(\bullet)+P \frac{k_{0}-1}{B^{2}}\right] \\
= & -\left(k_{0}-1\right)+\frac{2}{n(n-1)} \sum_{S \subseteq \Omega_{0}, \# S=2} \frac{B}{B(S)}+B^{\prime}\left(\Omega_{1}\right) \frac{P}{B}
\end{aligned}
$$

and therefore

$$
B^{\prime}>0 \Leftrightarrow \frac{2}{n(n-1)} \sum_{S \subseteq \Omega_{0}, \# S=2} \frac{B}{B(S)}+B^{\prime}\left(\Omega_{1}\right) \frac{P}{B}>k_{0}-1
$$

Using the first order condition (A4) for $\varepsilon=0$, we obtain

$$
\begin{aligned}
& \frac{P}{B}=\frac{k_{0}-H\left(\Omega_{0}\right)}{k_{0}-1} \\
& \frac{B}{B(S)}=\frac{k_{0}-H\left(\Omega_{0}\right)}{2-2 H\left(\Omega_{0}\right)+H(S)\left(k_{0}-1\right)}
\end{aligned}
$$

It remains to determine the change in contributions from new participants, i.e. $B^{\prime}\left(\Omega_{1}\right)$ when marginally increasing $\varepsilon=0$. For $i \in \Omega_{1}=\Omega_{\varepsilon} \backslash \Omega_{0}$, the first order condition (A4) implies

$$
\begin{gathered}
1-h_{i}{ }^{\prime}\left(B_{0}-P\right)-\frac{P}{B_{0}}=\frac{2}{n(n-1)} \lim _{\varepsilon \searrow 0} \varepsilon \sum_{j \in \Omega_{1} \backslash i} \frac{b_{j}}{\left(b_{i}+b_{j}\right)^{2}} \\
=\frac{2}{n(n-1)} \sum_{j \in \Omega_{1} \backslash i} \frac{b_{j}{ }^{\prime}}{\left(b_{i}{ }^{\prime}+b_{j}{ }^{\prime}\right)^{2}} \\
2-H(S)-2 \frac{P}{B_{0}} \geq \frac{2}{n(n-1)} \frac{1}{B^{\prime}(S)} \quad \text { for } S \subseteq \Omega_{1}, \# S=2 \\
B^{\prime}\left(\Omega_{1}\right) \geq \frac{2}{n(n-1)} \frac{1}{k_{1}-1} \sum_{S \subseteq \Omega_{1}, \# S=2} \frac{1}{2-H(S)-2 \frac{P}{B_{0}}}
\end{gathered}
$$

Therefore, plugging Eqs. (A6) and (A7) in Eq. (A5), a sufficient condition for $B^{\prime}>0$ is given by

$$
\begin{aligned}
\sum_{S \subseteq \Omega_{0}, \# S=2} & \frac{k_{0}-H\left(\Omega_{0}\right)}{2-2 H\left(\Omega_{0}\right)+H(S)\left(k_{0}-1\right)} \\
& +\sum_{S \subseteq \Omega_{1}, \# S=2} \frac{1}{k_{1}-1} \frac{k_{0}-H\left(\Omega_{0}\right)}{-2-H(S)\left(k_{0}-1\right)+2 H\left(\Omega_{0}\right)}>\frac{n(n-1)}{2}\left(k_{0}-1\right)
\end{aligned}
$$




\section{Appendix B. Experimental instructions - Symmetric TON treatment}

\section{B.1. General rules}

This is an experiment in economic decision making. If you follow the instructions carefully and make good decisions you can earn a considerable amount of money. You will be paid in private and in cash at the end of the session.

It is important that you do not talk, or in any way try to communicate, with other people during the session. If you have a question, raise your hand and a monitor will come over to where you are sitting and answer your question in private.

The experiment will consist of 12 rounds. The first 2 rounds will be practice. In each round, you will be randomly assigned to a group of 4 people. These groups will change each round. You will not know which of the other people in the room are in your group and the other people in the session will not know with whom they are grouped in any round.

In each round, you will have the opportunity to earn points. At the end of the session, one of the non-practice rounds will be randomly selected and you will be paid in cash an amount that will be determined by the number of points you earn during the randomly selected round.

\section{B.2. Description of each round}

At the beginning of the first trial round a subject number will be given on your terminal. Record that number on your record sheet. Each round you will be given an endowment of 100 tokens. At the beginning of each round, the computer will prompt you to enter the number of tokens you want to contribute to the group account. Enter a whole number between 0 and 100, record the number in column (b) on your record sheet, and click continue. Any tokens you do not place in your group account are placed in your private account. Once your decision is recorded, it cannot be changed. After everyone in your group has recorded their decisions, a screen will appear informing you of the number of tokens contributed to the group account by all group members, whether any bonus points have been earned, and your profit for the round. Record the information from that screen onto your record sheet as follows:

Tokens in private account Column A

Your contribution to group account Column B

Total tokens in group account Column C

Private account points Column D

Group account points Column E

Bonus 1 points Column $\mathrm{F}$

Bonus 2 points Column $\mathrm{G}$

Profit for round Column $\mathrm{H}$

Once everyone has recorded his or her information, the next round will begin.

\section{B.3. How earnings are determined}

The number of points you earn in the round will be determined as follows. For each token placed in your private account you will earn 1 point. This amount is recorded in column (d) on your record sheet. You will receive 0.3 points for each token placed in your group account by you 
and the other people in your group. The group account points are recorded in column (e) of the record sheet.

In addition, at the end of each round you will receive a share of 80 bonus points. At the end of each round, we will allocate Bonus 1 (40 points) amongst all group members and Bonus 2 (the remaining 40 points) amongst two randomly selected group members. Your share of Bonus 1 is determined by how much you contributed to the group account in that round. Specifically, your share of the 40 points will be equal to the number of tokens you place in the group account, divided by the total number of tokens placed in the group account by you and the other people in your group. For example, if your contribution is $50 \%$ of the total tokens placed in the group account, you will receive $50 \%$ of the initial bonus (20 points). If no tokens are placed in the group account, each member of the group will receive an equal share of Bonus 1 points.

The remaining 40 bonus points (Bonus 2) will be allocated in a similar manner amongst two group members randomly selected by a computer. The probability that any individual is selected to compete for Bonus 2 is independent of contribution decisions. Since these probabilities are identical for each individual, every member of a group has a $50 \%$ chance of being selected to compete for Bonus 2 and a one in six chance of being matched with any specific group member.

If you and another group member are randomly selected by the computer, your share of the 40 points from Bonus 2 will be equal to the number of tokens you place in the group account divided by the total number of tokens placed in the group account by you and the other selected individual. For example, if you place $40 \%$ of the tokens into the group account and the remaining three group members each place $20 \%$ of the tokens into the group account, you will receive $67 \%$ of Bonus 2 (27 points) if you are one of the two individuals selected by the computer.

Record any Bonus 1 points earned in column (f) on your record sheet and any Bonus 2 points earned in column $(\mathrm{g})$ on your record sheet. Your profit for the round is computed by summing the private account points, the group account points, the Bonus 1 points, and the Bonus 2 points. This total is recorded in column $(\mathrm{h})$ on the record sheet. At the end of the session we will draw a ticket from the box. In the box there is a numbered ticket for each round played (1-10). The number on the ticket that is drawn will determine the round for which you will be paid. Record the selected round and then your profit for that round in the space provided at the bottom of the record sheet. You will receive $\$ 1$ in cash at the end of the session for every 15 points you earn in that round. This amount is recorded in the space titled earnings.

\section{Appendix C. Experimental instructions - Asymmetric REB treatment}

\section{C.1. General rules}

This is an experiment in economic decision making. If you follow the instructions carefully and make good decisions you can earn a considerable amount of money. You will be paid in private and in cash at the end of the session.

It is important that you do not talk, or in any way try to communicate, with other people during the session. If you have a question, raise your hand and a monitor will come over to where you are sitting and answer your question in private.

The experiment will consist of 12 rounds. The first 2 rounds will be practice. In each round, you will be randomly assigned to a group of 4 people. These groups will change each round. You will not know which of the other people in the room are in your group and the other people in the session will not know with whom they are grouped in any round. 
In each round, you will have the opportunity to earn points. At the end of the session, one of the non-practice rounds will be randomly selected and you will be paid in cash an amount that will be determined by the number of points you earn during the randomly selected round.

\section{C.2. Description of each round}

At the beginning of the first trial round a subject number will be given on your terminal. Record that number on your record sheet. At the beginning of the session, you will be assigned a valuation for tokens placed in the group account of either 0.9 or 0.1 - in each round you will be matched in groups such that one member of each group has a valuation of 0.9 and the other three have valuations of 0.1 . For example, if there are 24 people in the session 6 would have a valuation of 0.9 and the other 18 would have valuations of 0.1 . In each round, the six groups would have one person with the high valuation and three others with the low valuation. These groups will be randomly rematched in every period but each group will contain exactly one person with the high valuation for the group account and three with the low valuation for the group account. Your valuation will be held constant throughout the session.

Each round you will be given an endowment of 100 tokens. At the beginning of each round, the computer will prompt you to enter the number of tokens you want to contribute to the group account. Enter a whole number between 0 and 100, record the number in column (b) on your record sheet, and click continue. Any tokens you do not place in your group account are placed in your private account. Once your decision is recorded, it cannot be changed. After everyone in your group has recorded their decisions, a screen will appear informing you of the number of tokens contributed to the group account by all group members, whether any bonus points have been earned, and your profit for the round. Record the information from that screen onto your record sheet as follows:

Tokens in private account Column A

Your contribution to group account Column B

Total tokens in group account Column C

Private account points Column D

Group account points Column E

Bonus points Column $\mathrm{F}$

Profit for round Column $\mathrm{G}$

Once everyone has recorded his or her information, the next round will begin.

\section{C.3. How earnings are determined}

The number of points you earn in the round will be determined as follows. For each token placed in your private account you will earn 1 point. This amount is recorded in column (d) on your record sheet. You will receive either 0.9 or 0.1 points (depending upon your valuation for the group account) for each token placed in your group account by you and the other people in your group. The group account points are recorded in column (e) of the record sheet.

In addition, at the end of each round you will receive a share of 80 bonus points. Your share of the bonus points is determined by how much you contributed to the group account in that round. Specifically, your share of the bonus points will be equal to the number of tokens you place in the group account, divided by the total number of tokens placed in the group account by you and the 
other people in your group. For example, if your contribution is $50 \%$ of the total tokens placed in the group account, you will receive $50 \%$ of the bonus (40 points). If no tokens are placed in the group account, each member of the group will receive an equal share of the bonus. Record any bonus points earned in column (f) on your record sheet. Your profit for the round is computed by summing the private account points, the group account points, and the bonus points. This total is recorded in column $(\mathrm{g})$ on the record sheet.

At the end of the session we will draw a ticket from the box. In the box there is a numbered ticket for each round played (1-10). The number on the ticket that is drawn will determine the round for which you will be paid. Record the selected round and then your profit for that round in the space provided at the bottom of the record sheet. You will receive $\$ 1$ in cash at the end of the session for every 15 points you earn in that round. This amount is recorded in the space titled earnings.

\section{Appendix D . Instructions-Part II (risk aversion measures)}

Record your subject number from the previous part on your decision sheet. Your decision sheet shows ten decisions listed on the left. Each decision is a paired choice between Option A and Option B. You will make ten choices and record these in the final column, but only one of them will be used in the end to determine your earnings. Before you start making your ten choices, please let me explain how these choices will affect your earnings for this part of the experiment.

We will use part of a deck of cards to determine payoffs; cards 2-10 and the Ace will represent "1". After you have made all of your choices, we will randomly select a card twice, once to select one of the ten decisions to be used, and a second time to determine what your payoff is for the option you chose, A or B, for the particular decision selected. (After the first card is selected, it will be put back in the pile, the deck will be reshuffled, and the second card will be drawn). Even though you will make ten decisions, only one of these will end up affecting your earnings, but you will not know in advance which decision will be used. Obviously, each decision has an equal chance of being used in the end.

Now, please look at Decision 1 at the top. Option A pays $\$ 8.00$ if the Ace is selected, and it pays $\$ 6.40$ if the card selected is $2-10$. Option B yields $\$ 15.40$ if the Ace is selected, and it pays $\$ 0.40$ if the card selected is $2-10$. The other Decisions are similar, except that as you move down the table, the chances of the higher payoff for each option increase. In fact, for Decision 10 in the bottom row, the cards will not be needed since each option pays the highest payoff for sure, so your choice here is between $\$ 8.00$ and $\$ 15.40$.

To summarize, you will make ten choices: for each decision row you will have to choose between Option A and Option B. You may choose A for some decision rows and B for other rows, and you may change your decisions and make them in any order. When you are finished, we will come to your desk and pick a card to determine which of the ten Decisions will be used. Then we will put the card back in the deck, shuffle, and select a card again to determine your money earnings for the OPTION you chose for that Decision. Earnings for this choice will be added to your previous earnings, and you will be paid all earnings in cash when we finish.

So now please look at the empty boxes on the right side of the record sheet. You will have to write a decision, A or B in each of these boxes, and then the card selection will determine which one is going to count. We will look at the decision that you made for the choice that counts, and circle it, before selecting a card again to determine your earnings for this part. Then you will write your earnings in the blank at the bottom of the page. 
Are there any questions? Now you may begin making your choices. Please do not talk with anyone else while we are doing this; raise your hand if you have a question.

Decision sheet

\begin{tabular}{ll}
\hline Option $A$ & Option B \\
\hline $1 / 10$ of $\$ 8.00,9 / 10$ of $\$ 6.40$ & $1 / 10$ of $\$ 15.40,9 / 10$ of $\$ 0.40$ \\
$2 / 10$ of $\$ 8.00,8 / 10$ of $\$ 6.40$ & $2 / 10$ of $\$ 15.40,8 / 10$ of $\$ 0.40$ \\
$3 / 10$ of $\$ 8.00,7 / 10$ of $\$ 6.40$ & $3 / 10$ of $\$ 15.40,7 / 10$ of $\$ 0.40$ \\
$4 / 10$ of $\$ 8.00,6 / 10$ of $\$ 6.40$ & $4 / 10$ of $\$ 15.40,6 / 10$ of $\$ 0.40$ \\
$5 / 10$ of $\$ 8.00,5 / 10$ of $\$ 6.40$ & $5 / 10$ of $\$ 15.40,5 / 10$ of $\$ 0.40$ \\
$6 / 10$ of $\$ 8.00,4 / 10$ of $\$ 6.40$ & $6 / 10$ of $\$ 15.40,4 / 10$ of $\$ 0.40$ \\
$7 / 10$ of $\$ 8.00,3 / 10$ of $\$ 6.40$ & $7 / 10$ of $\$ 15.40,3 / 10$ of $\$ 0.40$ \\
$8 / 10$ of $\$ 8.00,2 / 10$ of $\$ 6.40$ & $8 / 10$ of $\$ 15.40,2 / 10$ of $\$ 0.40$ \\
$9 / 10$ of $\$ 8.00,1 / 10$ of $\$ 6.40$ & $9 / 10$ of $\$ 15.40,1 / 10$ of $\$ 0.40$ \\
$10 / 10$ of $\$ 8.00,0 / 10$ of $\$ 6.40$ & $10 / 10$ of $\$ 15.40,0 / 10$ of $\$ 0.40$ \\
\hline
\end{tabular}

\section{References}

Andreoni, James, 1990. Impure altruism and donations to public goods: a theory of warm glow giving. Economic Journal 100, 464-477.

Andreoni, James, 1998. Toward a theory of charitable fundraising. Journal of Political Economy 106, 1186-1213.

Andreoni, James, Bergstrom, Ted, 1996. Do government subsidies increase the private supply of public goods? Public Choice 88, 295-308.

Bagnoli, Mark, McKee, Michael, 1991. Voluntary contribution games: efficient private provision of public goods. Economic Inquiry 29, 351-366.

Bergstrom, Ted, Blume, Larry, Varian, Hal, 1986. On the private provision of public goods. Journal of Public Economics 29, 25-49.

Dale, Donald, 2004. Charitable lottery structure and fund raising: theory and evidence”. Experimental Economics 7 , $217-234$.

Dunbar, Charles, 1888. Some precedents followed by Alexander Der Hamilton. Quarterly Journal of Economics 3, $32-59$.

Eckel, C., Grossman, P., 2003. Rebate versus matching: does how we subsidize charitable contributions matter? Journal of Public Economics 87, 681-701.

Engers, Maxim, McManus, Brian, 2002. Charity Auctions. Working Paper. University of Virginia.

Falkinger, Joseph, 1996. Efficient provision of public goods by rewarding deviations from averages. Journal of Public Economics 62, 413-422.

Fischbacher, Urs, 1999. Z-tree: Zurich toolbox for readymade economic experiments - experimenter's manual. Working Paper \#21, Institute for Empirical Research in Economics. University of Zurich.

Goeree, Jacob, Maasland, Emiel, Onderstal, Sander, Turner, John, 2005. How (not) to raise money. Journal of Political Economy 113, 897-918.

Groves, Theodore, Ledyard, John, 1977. Optimal allocation of public goods: a solution to the free rider problem. Econometrica 45, 783-809.

Holt, Charles, Laury, Susan, 2002. Risk aversion and incentive effects. American Economic Review 92, $1644-1655$.

Jennings, R., Swanson, D., Trout, A., 1988. Alexander Hamilton's tontine proposal. William and Mary Quarterly 45, $107-115$.

Landry, Craig, Lange, Andreas, List, John A., Price, Michael, Rupp, Nicholas, 2006. Toward and understanding of the economics of charity: evidence from a field experiment. Quarterly Journal of Economics 121, 747-782.

Lange, Andreas, List, John A., Price, Michael K., 2007. Using lotteries to finance public goods: theory and experimental evidence. International Economic Review 48 (3), 901-927.

List, John A., Lucking-Reiley, David, 2002. Effects of seed money and refunds on charitable giving: experimental evidence from a university capital campaign. Journal of Political Economy 110, 215-233.

Morgan, John, 2000. Financing public goods by means of lotteries. Review of Economic Studies 67, 761-784.

Morgan, John, Sefton, Martin, 2000. Funding public goods with lotteries: experimental evidence. Review of Economic Studies $67,785-810$. 
Ransom, Richard, Sutch, Roger, 1987. Tontine insurance and the Armstrong investigation. The Journal of Economic History 47, 379-390.

Sargeant, Adrian, Jay, Elaine, Lee, Stephen, 2006. Benchmarking charity performance: returns from direct marketing in fundraising. Journal of Nonprofit and Public Sector Marketing 16, 77-94.

Sugden, R., 1982. On the economics of philanthropy. Economic Journal 92, 341-350.

Sugden, Robert, 1984. Reciprocity: the supply of public goods through voluntary contributions. Economic Journal 94 , $772-787$.

Varian, Hal, 1994. Sequential contributions to public goods. Journal of Public Economics 53, 165-186.

Walker, Mark, 1981. A simple incentive compatible scheme for attaining Lindahl allocations. Econometrica 49, 65-71.

Weir, David, 1989. Tontines, public finance, and revolution in France and England, 1688-1789. The Journal of Economic History $49,95-124$. 